\title{
ОБЗОРЫ ЛИТЕРАТУРЫ
}

https://doi.org/10.17816/vto202027157-76

(C) Коллектив авторов, 2020

\section{ТЕРАПИЯ ТРАВМАТИЧЕСКИХ ПОВРЕЖДЕНИЙ СПИННОГО МОЗГА МАГНИТНЫМИ НАНОЧАСТИЦАМИ: ЭКСПЕРИМЕНТАЛЬНЫЕ АСПЕКТЫ ПЕРСПЕКТИВНОЙ ТЕХНОЛОГИИ}

\author{
С.В. Колесов, В.В. Швеи, М.Л. Сажнев, А.А. Пантелеев, Д.С. Горбатюк \\ ФГБУ «Национальный медицинский исследовательский центр травматологии и ортопедии им. Н.Н. Приорова» \\ Минздрава России, Москва, Россия
}

\begin{abstract}
В аналитическом обзоре предпринята попытка обобщения имеющихся данных по вопросу потенциального применения стволовых клеток, меченных магнитными наночастицами. В настоящее время эта проблема находится на экспериментальной стадии изучения, при этом имеюшиеся сведения неоднородны и требуют обобщения для формирования целостного взгляда на проблему. Установлено, что магнитные наночастицы не характеризуются иитотоксичностью и значительным изменением физиологических процессов клеток, могут захватываться при помощи различных клеточных механизмов. Клетки, содержащие наночастицы, могут мигрировать (смещаться) в зависимости от плотности линий магнитного поля. У лабораторных животных с травматическим повреждением спинного мозга, которым в порядке эксперимента проводилась терапия стволовыми клетками, меченными магнитными наночастицами, было зарегистрировано статистически достоверное улучшение неврологических функций. Данные об использовании метода в клинической практике на текущий момент весьма ограничены; решение вопроса требует дальнейших исследований.

К л ю ч е в ы е с л о в а: магнитные наночастицы, позвоночник, спинной мозг, повреждение

Конф ликт ин те ре сов: не заявлен

И с точн и к фи нан с и р в в н и я : исследование проведено без спонсорской поддержки
\end{abstract}

КАК ЦИТИРОВАТЬ: Колесов С.В., Швец В.В., Сажнев М.Л., Пантелеев А.А., Горбатюк Д.С. Терапия травматических повреждений спинного мозга магнитными наночастицами: экспериментальные аспекты перспективной технологии. Вестник травматологии и ортопедии им. Н.Н. Приорова. 2020;27(1):57-76. doi: https://doi.org/10.17816/vto202027157-76

\section{THERAPY OF TRAUMATIC INJURIES OF THE SPINAL CORD BY MAGNETIC NANOPARTICLES: EXPERIMENTAL ASPECTS OF PROMISING TECHNOLOGY}

\author{
S.V. Kolesov, V.V. Shvets, M.L. Sazhnev, A.A. Panteleev, D.S. Gorbatyuk \\ N.N. Priorov National Medical Research Center of Traumatology and Orthopaedics, Moscow, Russia \\ In this analytical review an attempt to sum up the available data in magnetite nanoparticle-marked stem cells \\ utilization is made. Now this question remains on the experimental study level. Available data is diversified and \\ needs an integral look to be taken. It is found that magnetite nanoparticles are non-toxic for the cells and do not \\ interrupt physiological metabolic pathways. They can also be captured by cell using different transporters. Cells \\ containing the magnetite nanoparticles can migrate along the magnetic flux lines. Animals with traumatic spinal \\ cord lesions that got the nanoparticles-containing cell therapy showed the neurological status improvement. There is \\ very little data in usage of this method in clinical practice; the solution of this problem requires more clinical trials. \\ K e y words: magnetite nanoparticles, spine, spinal cord, injury \\ Conflict of interest: the authors state no conflict of interest \\ F u n d ing: the study was performed with no external funding
}

TO CITE THIS ARTICLE: Kolesov SV, Shvets VV, Sazhnev ML, Panteleev AA, Gorbatyuk DS. Therapy of traumatic injuries of the spinal cord by magnetic nanoparticles: experimental aspects of promising technology. N.N. Priorov Journal of Traumatology and Orthopedics. 2020;27(1):57-76. (In Russ.). doi: https://doi.org/10.17816/vto202027157-76

\section{Список сокращений}

ИВЛ - искусственная вентиляция легких

BBB - неврологический функциональный тест Basso-Beattie-Bresnahan

IONPs - iron oxide nanoparticles, наночастицы на основе оксида железа

OEC - olfactory ensheating cells, ольфакторные глиальные клетки

MF - magnetic field - группа животных, которым в эксперименте накладывалось внешнее магнитное поле NP - nanoparticles - группа животных, которым в эксперименте имплантировались (инъецировались) стволовые клетки, меченные магнитными наночастицами

SCI - spinal cord injury - ранение/травматическое повреждение спинного мозга (в том числе в ходе эксперимента) 
Введение. Повреждения спинного мозга с его полным или частичным разрывом остаются серьезной проблемой травматологии и нейрохирургии. Такая травма характеризуется потерей нервных клеток, аксональной дегенерацией, выраженным неврологическим дефицитом, а также приводит к инвалидизации пациента. Несмотря на высокую интенсивность исследований, эффективная терапия травм спинного мозга до сих пор не выработана $[1,2]$. Основной задачей исследований является поиск методов, направленных на восстановление функции поврежденной нервной ткани в области травматического воздействия. Наиболее перспективной стратегией представляется комбинация двух методов: введение стволовых клеток в область травмы спинного мозга [3, 4] и использование магнитных наночастиц, модулирующих репаративный рост вновь образованной нервной ткани.

Чаще всего клетки вводятся: непосредственно в область травматического поражения; внутривенно; интраартериально; интратекально путем люмбальной пункции. Показано [5], что интекальное введение значительно эффективнее внутривенного, а также менее инвазивно по сравнению с прямым введением клеток в область поражения. В настоящее время стоит вопрос о методе, позволяющем достичь наиболее высокой концентрации клеток в зоне травматического поражения, а также ответить на вопросы об эффективности закрепления клеток в указанной зоне (англ. homing) и адресности связывания клеток с тканями именно данной зоны (англ. targeting). Ответом на этот вопрос может быть метод использования клеточных меток - магнитных (во всех рассматриваемых работах - ферромагнитных) наночастиц, в частности суперпарамагнитные частицы на основе оксидов железа (Superparamagnetic iron oxide nanoparticles - SPION; далее - магнитные наночастицы), особенности распределения которых in vivo могут быть исследованы с помощью магнитно-резонансной томографии (МРТ) $[6,7]$. На клетки, меченные этими частицами, может оказывать воздействие магнитное поле [8, 9], заставляющее их смещаться от места введения по направлению к определенным органам и тканям.

Согласно данным предыдущих работ, показана возможность подобного направления клеток при повреждениях ткани печени [10] или головного мозга [11], а также усиление связывания мезенхимальных стволовых клеток (Mesenchymal stem cells - MSC) с поверхностью здорового спинного мозга. В ранних работах использовалась магнитная система на основе постоянного магнита [12]. По данным одного из исследований [13], такая магнитная система обладает несколькими важными особенностями и преимуществами:

- магнитные силы, создаваемые в системе, достаточны по величине для миграции клеток, меченных ферромагнитными метками;

- применение системы позволяет направить меченные клетки в зону повреждения с высокой степенью точности, что подтверждено серией морфогистологических исследований. В частности, имеется вы- раженная корреляция между напряженностью магнитного поля в разных участках зоны повреждения (вычисленная математически) и фактическим пространственным распределением меченных клеток в зоне повреждения;

- некоторыми авторами [14] высказывается также предположение, что магнитное поле может приводить к механическому смещению магнитной метки, захваченной клеткой, что стимулирует пролиферацию и дифференцировку последней;

- применение системы, по мнению авторов, не ограничивается только лечением спинальных травм, но возможно также и в других случаях, когда требуется направленная доставка стволовых клеток под действием магнитного поля.

Сходные результаты получены и в экспериментальных исследованиях Н. Сhо и соавт. [15], на лабораторных животных (крысах), у которых механически повреждался спинной мозг. Согласно этим данным, восстановление нервной ткани происходило при воздействии магнитного поля в течение 8 ч в сутки на протяжении 4 нед, что свидетельствует о возможности включения стволовых клеток в процессы репарации спинного мозга.

Вместе с тем вопрос использования магнитных систем в сочетании с меченными магнитными наночастицами MSC в настоящее время освещен в литературе достаточно скудно и требует дальнейших исследований.

Сами магнитные наночастицы обладают рядом свойств, делающих их не только удобным средством для манипуляции клетками при наложении внешнего магнитного поля, но и хорошим контрастирующим веществом. J. Cores и соавт. [16] подчеркивали, что метод МРТ с использованием частиц на основе оксида железа характеризуется большей чувствительностью, чем при использовании некоторых стандартных контрастных веществ, например солей гадолиния. Частицы оксида железа могут быть обнаружены как в Т1-, так и в Т2-режимах проведения МРТ.

На эффективность захвата магнитных частиц клеткой напрямую влияет наличие либо отсутствие, а также тип покрытия. В настоящее время разработано достаточно много типов такого покрытия [17], однако наиболее часто можно встретить следующие.

1. Полиэтиленгликоль. Амфифильный полимер, связанный с оксидом железа путем ковалентных связей [18]. Такие частицы маловосприимчивы к поглощению макрофагами, характеризуются высокой биосовместимостью, а также не склонны к коррозии в гидрофильных средах и воздухе [19].

2. Декстран. Углеводный биополимер на основе повторяющихся гликопиранозных фрагментов. Связывается с ядром на основе оксида железа при помощи нековалентных связей, что потенциально может привести к отрыву оболочки при определенных условиях [20]. Для усиления связи оболочка-ядро декстран может быть карбоксилирован [20, 21]. Такие магнитные наночастицы применяются главным образом в лучевой диагностике (МРТ). Они характеризуются высокой биосовместимостью, высоким пери- 
одом биохимического полураспада и могут быть связаны с другими агентами (антителами, пептидами, производными небольших молекул).

3. Крахмал. Гидрофильный полимер D-глюкозы. Магнитные частицы с таким покрытием характеризуются нетоксичностью, возможностью биодеградации, а также высокой биосовместимостью.

4. Цитрат. Представляет собой относительно новый вид покрытия для магнитных наночастиц, имеет отрицательный заряд и создает высокую аффинность между магнитной частицей и клеткой. Показано также, что цитрат может влиять на процессы хондродифференцировки и хемотаксиса, однако требуются дополнительные исследования для установления границ терапевтических доз.

Существует 5 различных механизмов абсорбции наночастиц клеткой, а именно: пассивная диффузия, клатрин-опосредованный эндоцитоз, кавеолин-опосредованный эндоцитоз, фагоцитоз, макропиноцитоз.

1. Пассивная диффузия. Механизм не предполагает затрат энергии, с его помощью возможно переносить небольшие (до 20 нм) положительно заряженные частицы [22]. По исследованиям групп ученых, частицы после биохимической модификации могут мимикрировать под клеточные пептиды и захватываться более интенсивно [23].

2. Эндоцитоз. Как кларитин-опосредованный эндоцитоз, так и кавеолин-опосредованный эндоцитоз являются основными механизмами захвата частиц, которые не могут проникнуть в клетку по механизму пассивной диффузии. При кларитин-опосредованном фагоцитозе формируется лизосома, при кавеолин-опосредованном - кавеосома. Последняя характеризуется относительно низкой концентрацией лизирующих ферментов [24], что, возможно, имеет значение для сохранности первоначальной структуры магнитных наночастиц.

3. Фагоцитоз. Специфический тип захвата частиц, характерный прежде всего для макрофагов и моноцитов. Вероятность включения механизма зависит прежде всего от свойств покрытия магнитной частицы [24].

4. Макропиноцитоз - механизм, не характеризующийся какой-либо избирательностью в отношении размеров частиц и особенностей их покрытия. Частицы интернализируются путем образования макропиносом [24].

J. Cores и соавт. [16] сообщают также о перспективном методе доставки магнитных частиц, который в настоящее время находится в разработке. Метод предполагает связывание с частицами специализированных антител. Полученные конъюгированные структуры связываются с CD34-рецепторами на поверхности стволовых клеток, происходит захват и накопление частиц $[25,26]$.

\section{МАТЕРИАЛ И МЕТОДЫ}

Анализ литературы был проведен 6 ноября 2016 г. с использованием библиографической базы статей MedLine. Поиск был ограничен статьями на английском, русском и немецком языках. В силу крайней ограниченности доступной выборки все статьи, послужившие основой для настоящего обзора, написаны на английском языке. Использовались следующие ключевые слова: Spinal cord, Spinal cord injuries, Magnetite nanoparticles. Анализировались статьи с 2011 по 2016 г. включительно. В обзор включались статьи, соответствовавшие следующим критериям.

1. Содержавшие сведения об экспериментальном применении метода трансплантации стволовых клеток, меченных магнитными наночастицами, in vivo (на лабораторных животных). Эти статьи являются своего рода интегральным обобщением накопленных знаний по заданной теме и являются базисом для разработки клинических методов лечения:

- у всех животных имитировалось травматическое повреждение спинного мозга путем его пересечения в стерильных (операционных) условиях;

- в исследовании должны были принимать участие как минимум 32 лабораторных животных.

2. Содержавшие сведения о взаимодействии клеточных культур стволовых клеток с магнитными наночастицами при наложении магнитного поля in vitro, что дало бы дополнительную информацию для достижения цели исследования. Анализировались работы, содержавшие данные согласно одному или нескольким следующим аспектам:

- потенциальная возможность захвата клетками магнитных наночастиц;

- возможное влияние типа покрытия частиц на взаимодействие с клетками;

- распределение клеток в цитоплазме;

- влияние частиц на жизнеспособность (выживаемость) клеток, а также на способность образования отростков и электрофизиологическую активность (в зависимости от линии клеток);

- влияние наложения внешнего магнитного поля на пространственное распределение меченых клеток.

3. Содержавшие сведения о возможном применении исследуемого метода в качестве клинического эксперимента с участием пациентов-добровольцев с повреждением спинного мозга:

- минимальное время проспективного наблюдения составляло 1 мес.

- в исследование был вовлечен как минимум 1 пациент.

Тематика статей выборки была достаточно гетерогенна и включала в себя следующие подгруппы:

- исследование способности стволовых клеток линий SPC (глиальных), меченных магнитными наночастицами, к формированию межнейронных контактов и восстановлению таким образом нервной ткани спинного мозга -2 статьи $[27,28]$;

- исследование принципов миграции меченных частицами клеток во внешнем (наложенном) магнитном поле - 1 публикация [29];

- источники литературы, посвященные in vitro исследованию особенностей поглощения клетками наночастиц с различным покрытием, - 2 работы $[16,30]$;

- экспериментальные работы по имплантации магнитных наночастиц и оценке возможного восстановления нервной ткани после повреждения (с ис- 
пользованием лабораторных крыс в качестве животной модели) - 3 публикации [27, 31, 32];

- сообщение об экспериментальном клиническом применении метода у пациента-добровольца с повреждением спинного мозга - 1 статья [33].

Гетерогенность выборки ставила целью найти ответ навопрос о состоянии интересующей проблемы, перспективах развития и путях ее решения с учетом всей доступной на момент написания информации и аспектов.

В ходе поиска и проверки литературы на соответствие краткого содержания (abstract) на предмет соответствия исследуемой теме были проанализированы 33 статьи, из которых 15 были отобраны для анализа содержания полного текста. Из них, в свою очередь, с применением критериев отбора было выбрано 9 публикаций.

\section{Экспериментальные исследования}

Этот раздел является нетипичным для литературного обзора. Однако было принято решение включить его в работу по следующим причинам.

1. Тема работы характеризуется научной новизной, и круг работ по ней ограничен. Поэтому описание каждого исследования и деталей его выполнения представляет экспериментально-практический интерес и научную ценность.

2. Состав каждого из экспериментов в настоящее время определяется исследователем самостоятельно, нет стандартизованного протокола их проведения. В силу этого общее тезисное описание методов является недостаточным.

3. Указанные особенности планирования и проведения экспериментов могут представлять значительный интерес для авторов новых исследований либо воспроизведения уже существующих. Таким образом, эти различия и особенности целесообразно отразить в настоящем обзоре до результатов исследований.

В этом разделе анализируются данные работ, в которых освещен экспериментальный метод с использованием лабораторных животных как имеющий наибольшее значение в раскрытии темы обзора.

\section{1. Общие методы}

Основными этапами эксперимента являлись подготовка клеточной культуры стволовых клеток различных клеточных линий, маркировка их магнитными наночастицами, введение клеток лабораторным животным (крысам) в зону повреждения спинного мозга, наложение магнитного поля и исследование состояния поврежденной зоны по прошествии определенного периода времени. При этом использовались различные методы: функциональные пробы (с целью установить неврологический статус оперированных животных), гистологические исследования, МРТ. Проспективное исследование нервного статуса, выживаемости и состояния животных дизайном исследований не предусматривалось, так как по завершении функциональных исследований все животные умервщлялись для выделения фрагментов спинного мозга и проведения МРТ, гистологических и других исследований, требующих соответствующей подготовки материала.

\section{2. Источник клеток}

Единого мнения насчет оптимального источника клеток среди авторов нет. В каждом исследовании использовалась отличная от других клеточная линия; можно предположить, что это продиктовано доступностью той или иной клеточной линии в каждой отдельно взятой лаборатории, а также отсутствием каких бы то ни было рекомендаций либо стандартов проведения подобных экспериментов. В частности, во всех представленных работах, как будет показано ниже, все клеточные линии различны по своим свойствам. Уже на этапе раздела (Материал и методы) очевидно, что задача интегрального обобщения полученных экспериментальных данных значительно усложняется ввиду данного многообразия.

Многообразие клеточных линий можно классифицировать по двум основным признакам: происхождение (человеческое либо животное), а также по гистологическому признаку (табл. 1).

\section{3. Магнитные наночастицы}

Во всех описываемых работах в качестве основы для магнитных наночастиц использовался оксид железа (II, III) $\mathrm{Fe}_{3} \mathrm{O}_{4}$. (Исключением является использование дополнительно маггемита $\gamma-\mathrm{Fe}_{2} \mathrm{O}_{3}$ в работе M. Marcus и соавт. [30]). Применялись гранулы диаметром 10-50 нм, покрытые поли-L-лизином для обеспечения растворимости наночастиц в воде и облегчения адгезии клеток к субстрату (облегчения введения магнитных наночастиц в клетку на начальном этапе эксперимента до имплантации и наложения внешнего магнитного поля). Кроме того, для покрытия мог применяться крахмал либо декстран, а также покрытие могло отсутствовать. Наличие карбоксильных и аминогрупп у маггемитовых частиц без выраженного слоя покрытия, по М. Marcus и соавт. [30], объясняется особенностями технологии их получения [35], а нейтральный заряд магнетитовых с декстрановым покрытием - наличием вместе с анионами катионов, не являющихся функциональными группами (не участвующими во взаимодействии с клеткой) (табл. 2) [30].

\section{4. Исследования клеток и клеточных структур}

Сведения об экспериментальных исследованиях культур клеток имеются в 4 [30-32, 34] работах из 5 публикаций, описываемых в этом разделе статьи.

В одной из них [32] изучалось воздействие магнитного поля на культуру клеток, меченных магнитными наночастицами. При этом клетки помещались в чашку Петри (100 тыс. на 1 чашку), под которой располагался магнит. По прошествии 48 ч магнит убирали, клетки фиксировали параформальдегидом и изучали пространственное расположение и распределение клеток методом флюоресцентной микроскопии.

Во второй работе [31] исследование включало в себя определение выживаемости клеток после мечения их магнитными наночастицами в различных 
Табл. 1. Линии клеток, использованные в исследованиях

Table 1. Cell lines used in research

\begin{tabular}{|c|c|c|c|c|c|}
\hline № & Название линии & Происхождение & $\begin{array}{c}\text { Гистологический } \\
\text { признак }\end{array}$ & Примечание & Источник \\
\hline 1 & SPC-01 & Человеческие & Стволовые & $\begin{array}{c}\text { Стволовые клетки спинного мозга } 10 \text {-не- } \\
\text { дельного эмбриона человека }\end{array}$ & {$[27]$} \\
\hline 2 & GBM-U87 & Человеческие & Опухолевые & $\begin{array}{c}\text { Линия искусственно бессмертных клеток } \\
\text { из материала глиобластом и астроцитом че- } \\
\text { ловека }\end{array}$ & {$[31]$} \\
\hline 3 & SH-SY5Y & Человеческие & Опухолевые & Клетки из материала нейробластом человека & {$[30]$} \\
\hline 4 & OEC & Человеческие & Глиальные & $\begin{array}{c}\text { Olfactory Ensheating Cells, ольфакторные гли- } \\
\text { альные клетки }\end{array}$ & [34] \\
\hline 5 & $\begin{array}{l}\text { TgN (acro/act- } \\
\text { EFGP) 4Osb }\end{array}$ & Животные & Стволовые & $\begin{array}{c}\text { Стволовые клетки костного мозга бедренных } \\
\text { и большеберцовых костей трансгенных крыс } \\
\text { породы Sprague Dawley }\end{array}$ & [32] \\
\hline 6 & $\mathrm{PC}-12$ & Животные & Опухолевые & Линия клеток феохромоцитомы крыс & {$[30]$} \\
\hline
\end{tabular}

Табл. 2. Особенности различных типов магнитных наночастиц с точки зрения общей химии (по M. Marcus и coaвт. [30]) Table 2. Features of different types of magnetic nanoparticles in terms of General chemistry (by M. Marcus et al. [30])

\begin{tabular}{|c|c|c|c|c|c|}
\hline Тип частицы & $\begin{array}{c}\text { Гидродинамический } \\
\text { диаметр, нм }\end{array}$ & $\begin{array}{c}\text { Диаметр «сухой» } \\
\text { частицы, нм }\end{array}$ & $\begin{array}{c}\text { Заряд на по- } \\
\text { верхности }\end{array}$ & Покрытие & $\begin{array}{l}\text { Функциональные } \\
\text { группы покрытия }\end{array}$ \\
\hline Магнетитовые без покрытия & 100 & 10 & $\begin{array}{c}\text { Положитель- } \\
\text { ный }\end{array}$ & - & - \\
\hline $\begin{array}{l}\text { Магнетитовые с крахмальным } \\
\text { покрытием }\end{array}$ & 100 & 10 & Нейтральный & Крахмал & Гидроксильные \\
\hline $\begin{array}{l}\text { Магнетитовые с декстрановым } \\
\text { покрытием }\end{array}$ & 100 & 10 & Нейтральный & Декстран & Сульфатные \\
\hline Маггемитовые без покрытия & 200 & 20 & Анионный & - & $\begin{array}{c}\text { Карбоксильные, } \\
\text { аминогруппы }\end{array}$ \\
\hline
\end{tabular}

концентрациях. Использовалась 96-ячеистая культуральная плашка, в каждую из ячеек которой помещалось по 5000 клеток; затем по прошествии 24 ч добавлялся раствор магнитных наночастиц в концентрации 10, 25, 50 или 100 мкг/мл. Далее так называемым методом исключения трипанового синего (англ. trypan-blue exclusion method) подсчитывались жизнеспособные и нежизнеспособные клетки; для первых определялась процентная доля от общего количества.

B рамках третьей работы - исследования C. Riggio и соавт. [34], выполненного с применением ольфакторных глиальных клеток, клетки маркировались магнитными наночастицами (24 ч культивации), далее при помощи рентгеновской спектроскопии решался вопрос о количестве магнитных частиц-меток в цитоплазме. По методу проточной цитометрии определялась жизнеспособность клеток после поглощения магнитных частиц; на клетки воздействовали магнитным полем в течение 12 ч, и при помощи флюоресцентной микроскопии изучалось распределение клеток в чашке Петри.

Особого внимания заслуживает работа M. Marcus и соавт. [30], полностью посвященная вопросам «поглощения» клетками магнитных наночастиц. Использовались клетки феохромоцитомы крыс линии РС12, а также клетки нейробластомы человека линии SHSY5Y. Исследовались свойства магнитных частиц четырех типов: 1) минеральные кристаллы маггемита (maghemite), или $\gamma-\mathrm{Fe}_{2} \mathrm{O}_{3} ; 2$ ) частицы магнетита $\left(\mathrm{Fe}_{3} \mathrm{O}_{4}\right)$ без покрытия, несущие на поверхности по- ложительный заряд (nano-screenMAG-UC/C, производство «Chemicell», Berlin); 3) частицы магнетита, покрытые крахмалом (nano-screenMAG-D); 4) частицы магнетита, покрытые декстрансульфатом (nanoscreenMAG-DXS). Далее производилась инкубация клеток с магнитными наночастицами. Для определения захвата частиц использовался метод проточной цитофлоуметрии, а также иммунофлюоресцентное исследование.

\section{Исследования на модели поврежденного спинного мозга}

Оперативное вмешательство (имплантация меченных магнитными наночастицами стволовых клеток) проводилось на самцах лабораторных крыс породы Wistar. Число крыс в каждом из исследований составило от 32 до 83, масса 270-300 г (2 исследования) [27, 32], 200-250 г [31]. В асептических условиях после анестезии $2 \%$ изофлураном по срединной линии на уровне ThVII-ThXII рассекались кожа и мягкие ткани (межостистые связки), далее вводился катетер Фогарти с баллоном на конце до уровня ThVIIIThIX. Быстрым введением физиологического раствора баллон расширяли и повреждали спинной мозг. Наряду с контузионной моделью в некоторых работах имела место и резекция (пересечение спинного мозга) [31]. Место повреждения могло зондироваться для исключения контактирования пересеченных фрагментов спинного мозга [31]. Через 1 нед после операции клетки имплантировались в зону повреж- 
дения и устанавливался магнитный имплантат. Такой срок, по мнению авторов [36], обусловлен тем, что за 1 нед стихает реактивное воспаление, препятствующее нормальной имплантации стволовых клеток, однако глиальная прослойка, с функциональной точки зрения являющаяся аналогом соединительнотканных элементов в нервной ткани, еще не образована. По прошествии разных промежутков времени крысы выводились из эксперимента, приготавливались срезы спинного мозга (поперечные и продольные) для МРТ и гистологических исследований.

\section{Обработка статистических данных}

Обработка статистических данных осуществлялась с использованием программного обеспечения, доступного в той или иной лаборатории. Основными параметрами являлись среднее значение признака, а также среднеквадратичное отклонение. Сравнение результатов для различных групп животных производилось с помощью $t$-критерия Стьюдента, в одной из работ [31] дополнительно применялись тесты Краскела-Уоллиса и Манна-Уитни.

\section{Клиническое применение}

На текущий момент имеются сведения об одной работе, в которой было описано клиническое наблюдение (clinical case) [33]. У пациента с повреждением шейного отдела спинного мозга производился отбор 200 мл вещества красного костного мозга, содержавшего MSC костного мозга (англ. bone marrow-derived mesenchymal stem cells). Забор производился из гребня подвздошной кости пункционным методом. Отделение мононуклеарных стволовых клеток производилось методом центрифугирования по градиенту плотности Ficoll-Нураque. Мононуклеарные клетки культивировались в среде Dulbecco's Modified Eagle's Medium (DMEM) и 10\% растворе фетальной плазмы крови быков (fetal bovine serum) при $37{ }^{\circ} \mathrm{C}$ в атмосфере с повышенной влажностью и $5 \%$ содержанием углекислого газа. Среда, в которой культивировались клетки, замещалась каждые 4 сут. С целью увеличения числа клеток последние инкубировались в течение 4 нед. В качестве «целевого» было принято число клеток в 30·106. Производились бактериологические посевы культуры с отрицательным результатом. Половина клеток культуры $\left(15 \cdot 10^{6}\right)$ были отобраны для маркировки магнитными наночастицами (вводились в среду в концентрации 100 мкг/мл в комбинации с трансфекционным средством протамин-сульфат). Инкубация клеток составила 2 ч, затем к культуре была добавлена среда DMEM для достижения концентрации магнитных наночастиц в 50 мкг/мл, после чего производилась заключительная 12-часовая инкубация и клетки отмывались в фосфатном буферном растворе с гепарином в концентрации последнего 10 единиц фармакопеи США (US Pharmacopeia USP). Маркированные магнитными частицами и немаркированные клетки смешивались и помещались в физиологический раствор. Путем спинномозговой (люмбальной) пункции клетки вводились в субарахноидальное пространство, осуществлялся МРТ- контроль попадания клеток в необходимую область. Затем пациент находился в положении Тренделенбурга 24 ч. Периодически на разных сроках с момента вмешательства пациента осматривали неврологически для выявления клинического эффекта трансплантации клеток в динамике.

\section{Результаты экспериментальных исследований клеток и клеточных структур}

Пространственное распределение клеток в магнитном поле

Этот вопрос достаточно широко освещен в работе V. Vaněček и соавт. [32]. Авторами показано, что в отсутствие наложенного внешнего магнитного поля меченные магнитными частицами клетки располагаются хаотично и однородно, в то время как наложение магнитного поля изменяет их расположение (рис. 1).

Данные V. Vaněček и соавт. [32] были дополнены исследованием V. Zablotskii и соавт. [29], изучавшими особенности распределения клеток линии MSC на микромагнитах квадратной формы со стороной 100 мкм. Целью авторов являлось определение пространственной миграции меченных магнитными наночастицами клеток под действием магнитного поля. Авторы выявили, что под влиянием магнитного поля клетки смещаются к месту наибольшей концентрации линий напряженности магнитного поля (рис. 2, 3).
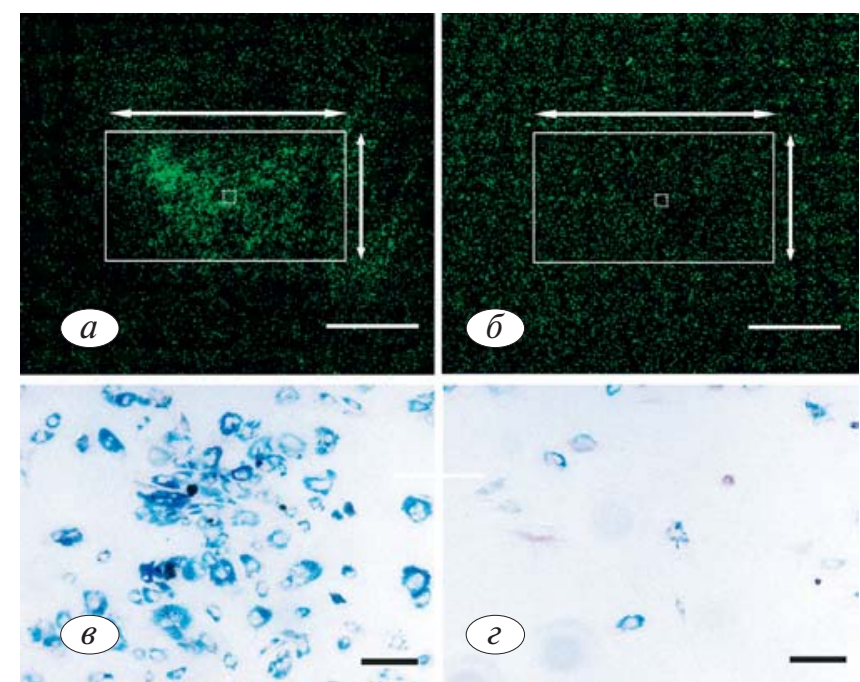

Рис. 1. Пространственное распределение клеток в магнитном поле (по V. Vaněček и соавт. [32]). Белый прямоугольник - границы магнита.

$a-$ клетки при наложении внешнего магнитного поля; 6 - клетки без наложения поля; в и г-увеличенные области белых квадратов в центре $a$ и $\sigma$ соответственно. Масштаб: $a, \sigma-$ горизонтальная линия 5000 мкм; в и г - 50 мкм. Окраска: $a$, $\sigma-$ зеленый флюоресцентный белок (green fluorescent protein - GFP), в, г - берлинская лазурь (prussian blue).

Fig. 1. Spatial distribution of cells in a magnetic field (by V. Vaněček et al. [32]). The white rectangle is the border of the magnet. a-cells with the imposition of an external magnetic field; b-cells without the imposition of the field; $\mathrm{C}$ and d-increased area of white squares in the center of a and $\mathrm{b}$, respectively. Scale: $a, b-$ horizontal line 5000 microns; $\mathrm{C}$ and g-50 microns. Color: $a, b-$ green fluorescent protein (green fluorescent protein-GFP), $b, g-$ Prussian blue (Prussian blue) 


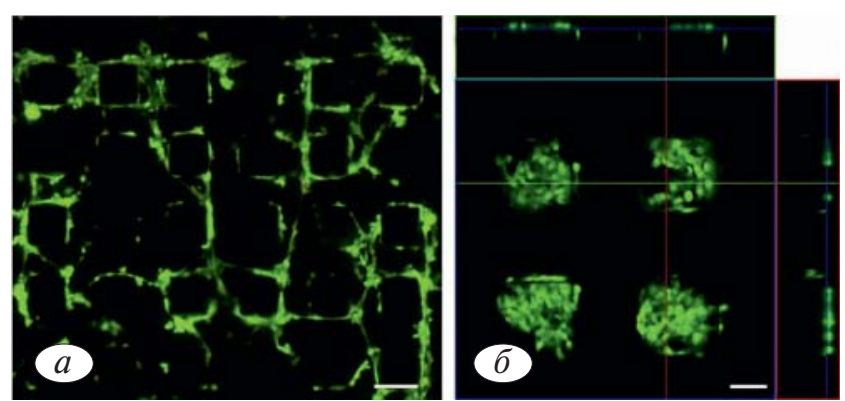

Рис. 2. Клетки линии MSC после посева на поверхность с квадратными магнитами $(100 \times 100$ мкм).

$a-4$ ч с момента посева, $\sigma-3$ сут с момента посева. Масштаб: горизонтальная линия на рис. $a-100$ мкм, $\sigma-50$ мкм. Окраска - GFP (по V. Zablotskii и соавт. [29]).

Fig. 2. Cells of the MSC line after «sowing» on the surface with square magnets ( $100 \times 100$ microns). $a-4 \mathrm{~h}$ from the moment of sowing, $b-$ 3 days from the moment of sowing. Macheadquarters: the horizontal line in Fig. $a-100$ microns, $b-50$ microns. Coloration-GFP (by V. Zablotskii et al. [29]).

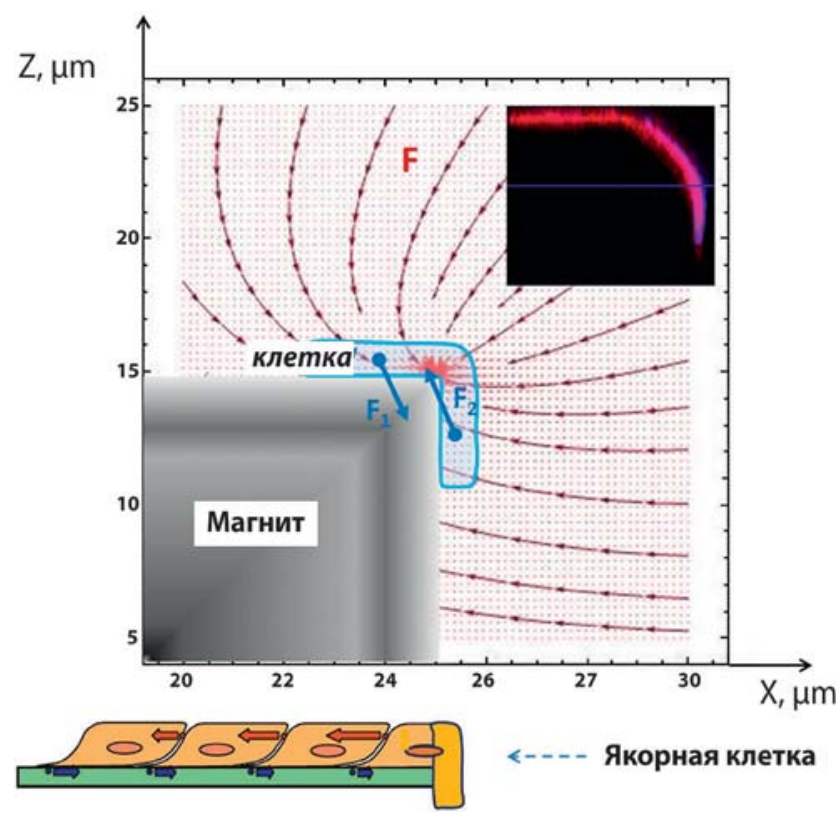

Рис. 3. Основные принципы распределения клеток относительно линий магнитного поля. Z и X - оси координат.

F1, F2 - примеры магнитных сил, смещающих клетку к углу магнита, где находится его полюс и плотность линий поля максимальна. Синие линии на нижнем рисунке - магнитные силы, красные - направления пролиферации в сторону от якорной клетки (anchor cell) (по V. Zablotskii и соавт. [29].)

Fig. 3. Basic principles of cell distribution relative to magnetic field lines. $\mathrm{Z}$ and $\mathrm{X}$ are the coordinate axes. F1, F2-examples of magnetic forces that shift the cell to the corner of the magnet, where is its pole and the density of the field lines is maximal. The blue lines in the lower figure - the magnetic forces, red-the direction of proliferation away from the» anchor « cell (by V. Zablotskii et al. [29].)

Значительный интерес для понимания принципов распределения меченных магнитными наночастицами клеток во внешнем магнитном поле представляет предложенная авторами физико-математическая модель. Основные прикладные положения ее сводятся к следующим тезисам:
- клетки, несущие на себе магнитную метку, мигрируют в сторону большей плотности линий магнитного поля (например, в сторону полюса магнита);

- пролиферация клеток идет от центра к периферии, в качестве центра выступает якорная клетка в месте наибольшей напряженности магнитного поля.

Таким образом, можно заключить, что наложение внешнего магнитного поля действительно влияет на пространственное расположение клеток, т.е. способствует их смещению в направлении максимальной плотности линий магнитного поля, что может быть полезным для адресной (топографически) доставки таких клеток в зону повреждения спинного мозга.

\section{Захват магнитных частии, и распределение} их в клетках

Исчерпывающий (по состоянию на текущий момент) ответ на вопрос об особенностях захвата магнитных наночастиц и распределения клеток в наложенном внешнем магнитном поле дается в работе M. Marcus и соавт. [30].

Авторами сделан вывод, что магнитные наночастицы с различными характеристиками покрытия взаимодействуют с клетками различным образом (в этом случае рассматривались клетки линии РС-12) (рис. 4). Изображения, полученные с использованием флюоресцентной конфокальной микроскопии, свидетельствуют, что магнетитовые частицы без покрытия оседали на внешней мембране клеток, не захватываясь ими. Так, из рис. 5 видно, что красное флюоресцентное свечение локализуется в области мембраны. Частицы с крахмальным покрытием связаны с внешней мембраной неравномерно, в виде своеобразных конгломератов. Частицы с декстрановым покрытием клетками также не захватывались. Вместе с тем маггемитовые частицы без покрытия обнаруживались в клетках в значительном количестве (так, по результатам флюоресцентной микроскопии, высокая интенсивность свечения наблюдалась внутри клеток). По данным работ $[37,38]$, гидродинамический диаметр всех типов рассмотренных частиц является оптимальным для их захвата нефагоцитирующими клетками, хотя исход (успешность) такого захвата значительно варьирует.

\section{Цитотоксичность}

Рассматривается вопрос о цитотоксичности разных видов частиц. По мнению авторов, данное свойство зависит от ряда факторов: наличия покрытия наночастиц и его типа, типа (линии) клеток, степени агрегации частиц к клеткам, однако главную роль играют характеристики покрытия, при этом магнитное «ядро» частицы свой вклад в цитотоксичность не вносит [37, 39, 40]. Так, маггемитовые частицы без покрытия не обладают выраженной цитотоксичностью, позволяющей клеткам аккумулировать их в больших количествах без вреда для себя, что свидетельствует в пользу их применения в высоких концентрациях (0,1 мг/мл и более). Кроме того, по данным авторов [41, 42], такие частицы, накопленные клетками в различных концентрациях, могут служить свое- 

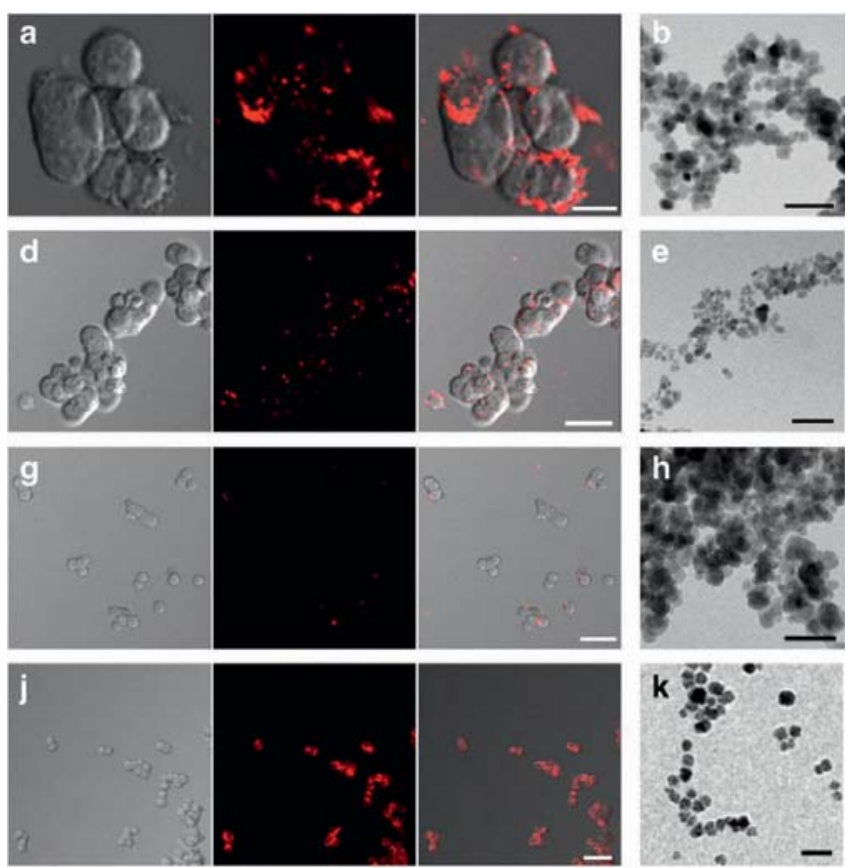

Рис. 4. Особенности захвата различных типов магнитных наночастиц (по М. Marcus и соавт. [30]).

Верхний ряд: магнетитовые частицы без покрытия; 2-й ряд: магнетитовые с крахмальным покрытием; 3-й: магнетитовые с декстрановым покрытием; 4-й: маггемитовые без покрытия. Слева и в центре - конфокальная флюоресцентная микроскопия, справа - электронная. Масштаб: горизонтальная линия - 50 нм.

Fig. 4. Features of capture of different types of magnetic nanoparticles (by M. Marcus et al. [30]). Top row: uncoated magnetite particles; 2nd row: magnetite with starch coating; 3rd row: dextran coated magnetite; 4th row: uncoated maghemite. Confocal fluorescence microscopy on the left and center, electron microscopy on the right. Scale: horizontal line- $50 \mathrm{~nm}$.

го рода контрастным веществом при МРТ. По мнению авторов настоящей работы, этот фактор может оказаться ценным при изучении адгезии меченных частицами клеток к поврежденным тканям, включая нервную, при спинальной травме.

Необходимо обратить внимание на тот факт, что захваченные магнитные наночастицы находятся исключительно в цитоплазме клеток, не проникая (не транспортируясь) в ядро, не нарушая, таким образом, митотические процессы и соответственно не ухудшая выживаемость (рис. 6).

Заслуживающее особого внимания мнение о возможной цитотоксичности магнитных наночастиц высказывается в работе A. Pal и соавт. [31]. С точки зрения авторов, частицы на основе магнетита $\mathrm{Fe}_{3} \mathrm{O}_{4}$ не только не обладают выраженной цитотоксичностью сами по себе, но и оказывают защитное воздействие, купируя либо ослабляя процессы перекисного окисления путем блокирования свободных радикалов. В эксперименте свободные радикалы создавались добавлением в среду пероксида водорода. Из диаграммы, приведенной в работе [31], наглядно видно, что введение магнитных наночастиц лишь незначительно снижает выживаемость клеток, однако по сравнению с эффектом пероксида водорода вы-
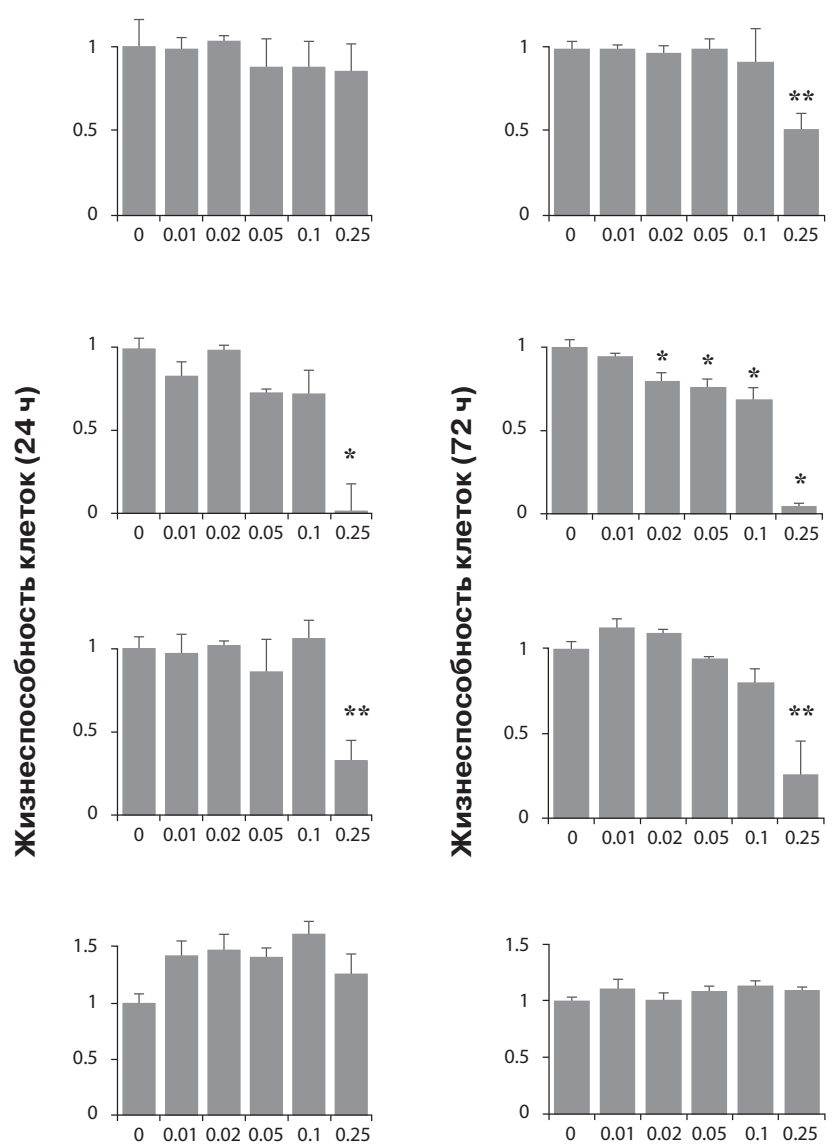

На всех графиках по оси абсцисс - концентрация наночастиц (мг/мл)

Рис. 5. Выживаемость клеток линии РС-12 после введения в среду магнитных частиц.

1-й ряд: результаты для магнетитовых частиц без покрытия; 2-й ряд: магнетитовые частицы с крахмальным покрытием; 3-й ряд: магнетитовые частицы с декстрановым покрытием; 4-й ряд: маггемитовые частицы без покрытия.

Примечание. ${ }^{*}-p<0,05 ;{ }^{* *}-p<0,01$ (по М. Marcus и соавт. [30]).

Fig. 5. Survival of RS-12 cells after administration.

in the environment of the magnetic particles. 1st row: results for uncoated magnetite particles; $2^{\text {nd }}$ row: starch-coated magnetite particles; $3^{\text {rd }}$ row: dextran-coated magnetite particles; $4^{\text {th }}$ row: uncoated maghemite particles.

Note. ${ }^{*}-p<0.05 ; * *-p<0.01$ (according to M. Marcus et al. [30]).

живаемость клеток, к которым добавили сочетание пероксид водорода + магнитные наночастицы, существенно выше (рис. 7).

Предложенный авторами механизм данного защитного эффекта заключается в связывании оксидом железа (II) гидроксид-радикалов (продукта распада пероксида водорода) с окислением железа из $\mathrm{Fe}^{2+}$ в $\mathrm{Fe}^{3+}$ и последующим восстановлением.

Влияние магнитных наночастии на ветвление отростков клеток

В работе M. Marcus и соавт. [30] присутствует заслуживающий отдельного рассмотрения тезис: клетки линии РС-12 исходно обладают способностью к ветвлению, т.е. образованию отростков. Одной из задач, которые решали авторы этого исследования, был ответ на вопрос: влияет ли захват клетками магнитных наночастиц на ветвление клеток. 

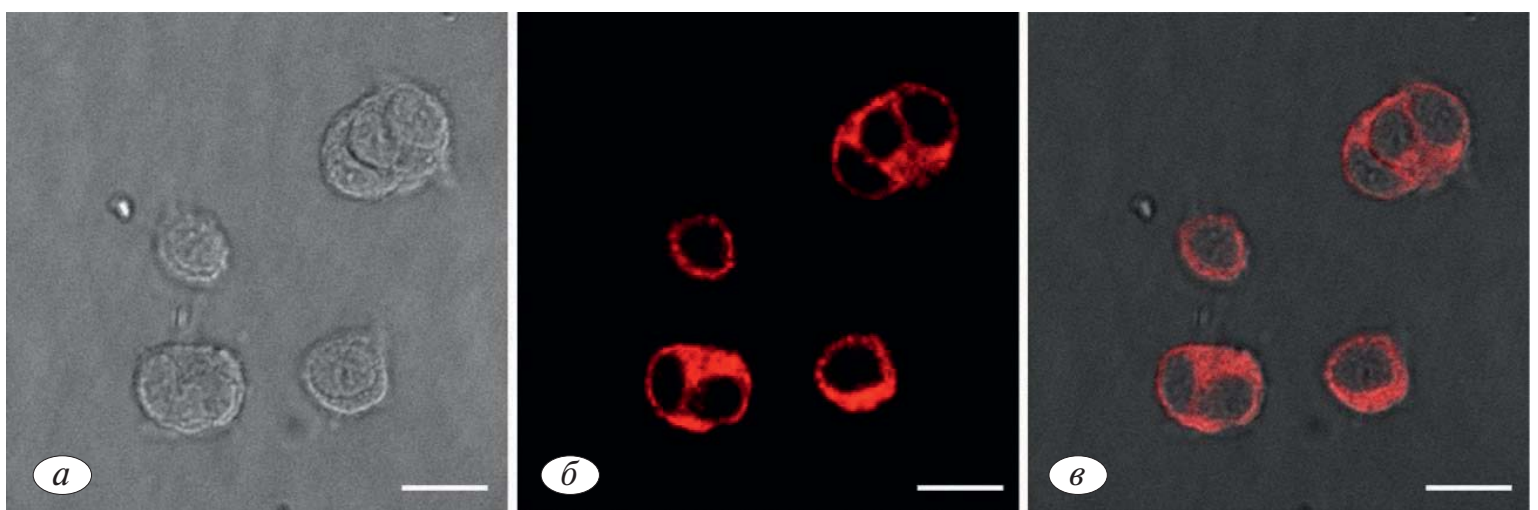

Рис. 6. Изображения, полученные методом конфокальной микроскопии клеток линии РС-12 по прошествии 24 ч инкубации с маггемитовыми наночастицами без покрытия. Частицы маркированы родамином (rhodamine).

$a$ - фазово-контрастное изображение; 6 - флюоресцентная микроскопия; в - совмещенное изображение (по М. Marcus и соавт. [30]).

Fig. 6. Images obtained by confocal microscopy of RS-12 cells after $24 \mathrm{~h}$ incubation with uncoated maghemite nanoparticles. The particles are labeled rhodamine (rhodamine). $a$ - phase-contrast image; $b$ - fluorescence microscopy; $c$ - combined image (by M. Marcus et al. [30]).

a

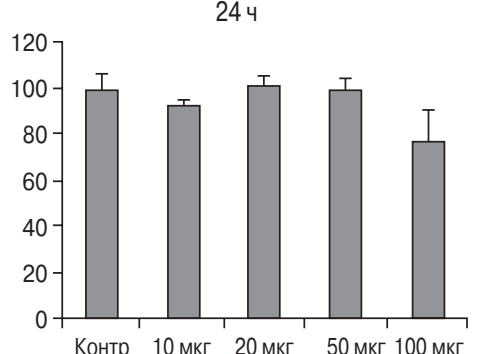

6

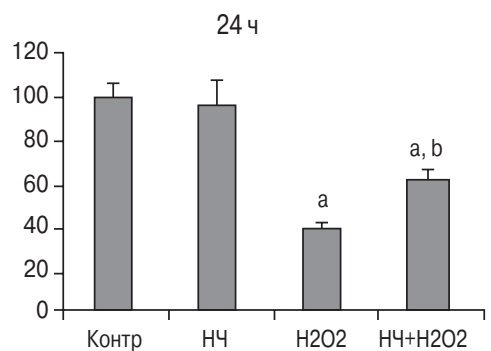

484

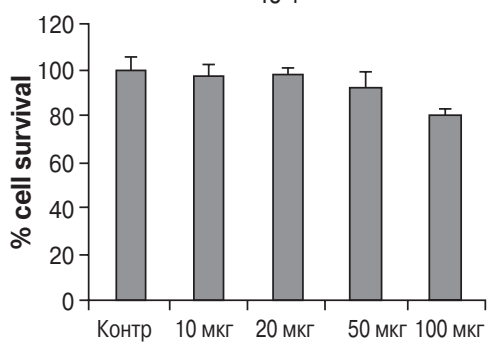

484

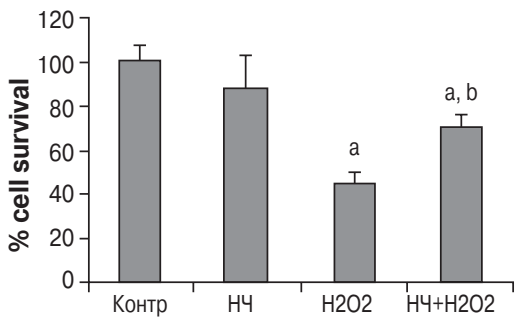

724

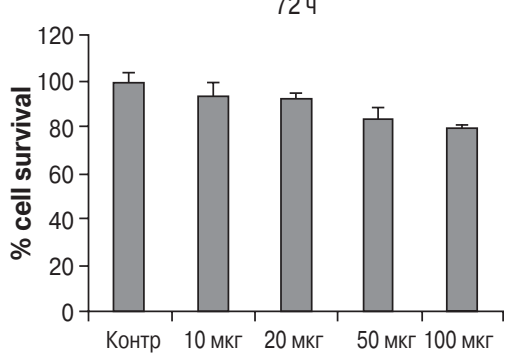

724

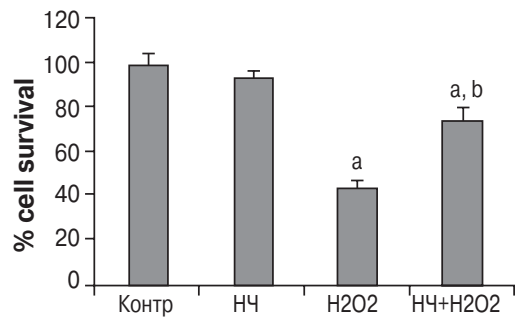

Рис. 7. Защитный эффект магнитных наночастиц в отношении стволовых клеток, трансплантируемых с целью терапии травматических повреждений спинного мозга.

Ряд а: процент выживших клеток при инкубации с различными концентрациями магнитных наночастиц. Ряд б: результат инкубации клеток с добавлением пероксида водорода (10 ммоль/мл), магнитных наночастиц (25 мкг/мл) либо их комбинации (по А. Раl и соавт. [31]).

Fig. 7. Protective effect of magnetic nanoparticles on stem cells transplanted for the treatment of traumatic spinal cord injuries. Row $a-$ percentage of cells that survived incubation with different concentrations of magnetic nanoparticles. Row $b-$ the result of cell incubation with the addition of hydrogen peroxide $(10 \mathrm{mmol} / \mathrm{ml})$, magnetic nanoparticles $(25 \mu \mathrm{g} / \mathrm{ml})$ or a combination thereof (according to A. Pal et al. [31]).

Полученные данные имеют значительную ценность, так как процессы образования клеточных отростков напрямую связаны с процессами построения (организации) цитоскелета клеток как линии РС-12, использованной в эксперименте, так и потенциально перспективных (с клинической точки зрения) стволовых клеток, которые предполагается использовать для лечения травматических повреждений спинного мозга. Результаты, полученные в ходе исследования, наглядно представлены на рис. 9.

Как отмечалось выше, M. Marcus и соавт. [30] также проведена работа на клетках линии SH-SY5Y (на основе клеток нейробластомы человека) и на нейронах пиявок. Исследовались как возможность захвата магнитных частиц (маггемитовые без покрытия) клетками, так и электрофизиологическая активность нейронов. Были выявлены следующие аспекты:

- клетки указанных типов обладают способностью захватывать магнитные наночастицы без каких-либо нарушений дифференцировки и развития. Частицы концентрируются в цитоплазме, не проникая в ядро;

- электрофизиологическая активность нейрональных клеток остается ненарушенной (близкой к физиологической) после захвата магнитных наночастиц. В частности, сохраняется способность клеток к формированию потенциалов действия, а также их вольтаж и форма (в графическом представлении) (рис. 10). 


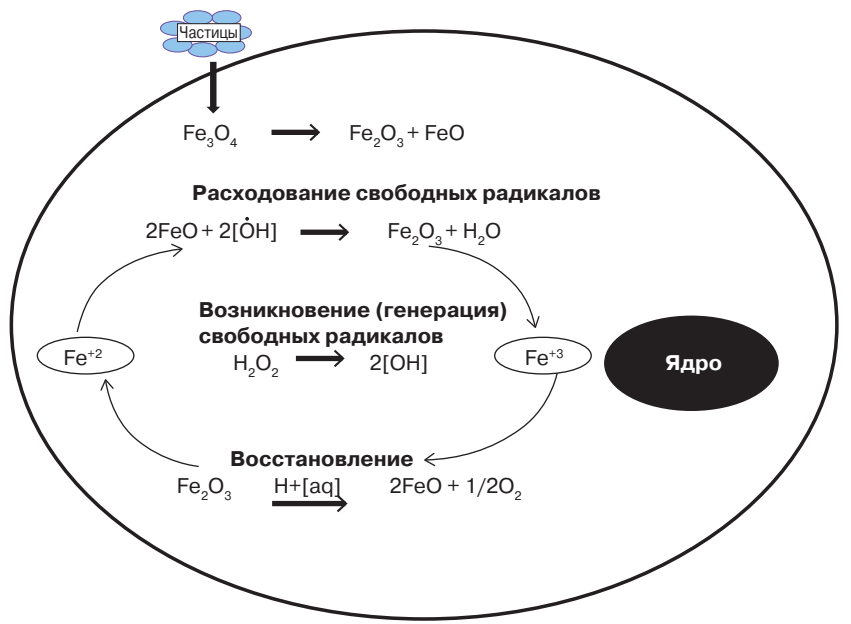

Рис. 8. Механизм цитопротективного действия магнитных наночастиц (по А. Pal и соавт. [31]).

Fig. 8. Mechanism of cytoprotective action of magnetic nanoparticles (by A. Pal et al. [31]).
Авторы пришли также к следующим выводам:

- клетки линии РС-12 полностью сохраняют свою способность к росту и дифференцировке, а также нормальному функционированию цитоскелета, что показано на примере развития отростков;

- сходные результаты показаны также для клеток линии SH-SY5Y (клетки из материала нейробластом человека) и нейронов пиявок. У последних была также исследована электрическая активность клеток, по своим характеристикам не отличающаяся от физиологической (включая формирование потенциалов действия типичной формы).

Таким образом, на основании совокупности всех полученных данных можно утверждать, что введение магнитных наночастиц и поглощение их клетками не наруша.т рост и развитие клеток, что в свою очередь позволяет рассматривать магнитные частицы как подходящие метки и направители (при наложении внешнего магнитного поля) для стволовых клеток. Что еще более важно, введение магнитных наночастиц
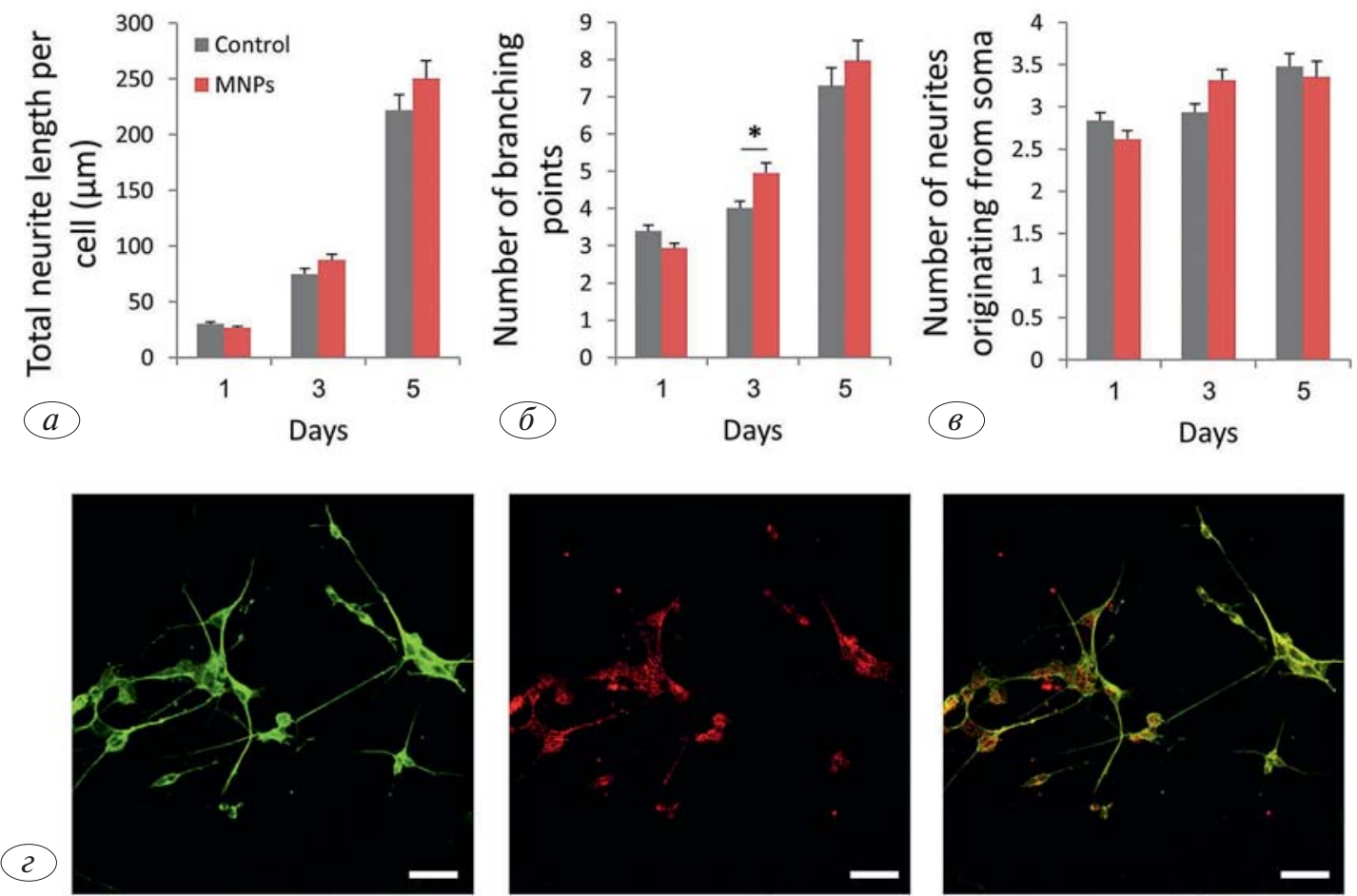

Рис. 9. Морфологические данные клеток линии РС-12 и особенности их ветвления. Данные были получены через 1, 3 и 5 сут после введения в среду магнитных наночастиц (маггемитовые без покрытия, 0,25 мг/мл); серые столбцы — группа контроля, красные клетки с введением наночастиц.

$a$ - длина отростков в микрометрах; $\sigma$ - число точек ветвления; 8 - число отростков, локализующихся на теле клетки; 2 - флюоресцентно-микроскопическая картина клеток (5 сут после введения магнитных частиц). Слева - свечение антител к альфа-тубулину; в центре - флюоресцентное свечение захваченных магнитных частиц; справа - совмещенное изображение. Горизонтальная линия -50 мкм.

Примечание. * ${ }^{*} p<0,05$ (по М. Мarcus и соавт. [30]).

Fig. 9. Morphological data of RS-12 cells and peculiarities of their branching. The data were obtained 1, 3 and 5 days after the introduction of magnetic nanoparticles (uncoated maghemite, $0.25 \mathrm{mg} / \mathrm{ml}$ ) into the medium; gray columns - the control group, red - cells with the introduction of nanoparticles.

$a$ - the length of the processes in micrometers; $b$ - the number of branching points; $c$ - the number of processes localized on the cell body; $g$ - fluorescence microscopic picture of cells ( 5 days after the introduction of magnetic particles). On the left-the glow of antibodies to alphatubulin; in the center-the fluorescent glow of captured magnetic particles; on the right - the combined image. The horizontal line is 50 microns.

Note. ${ }^{*}-\mathrm{p}<0.05$ (according To M. Marcus et al. [30]) 

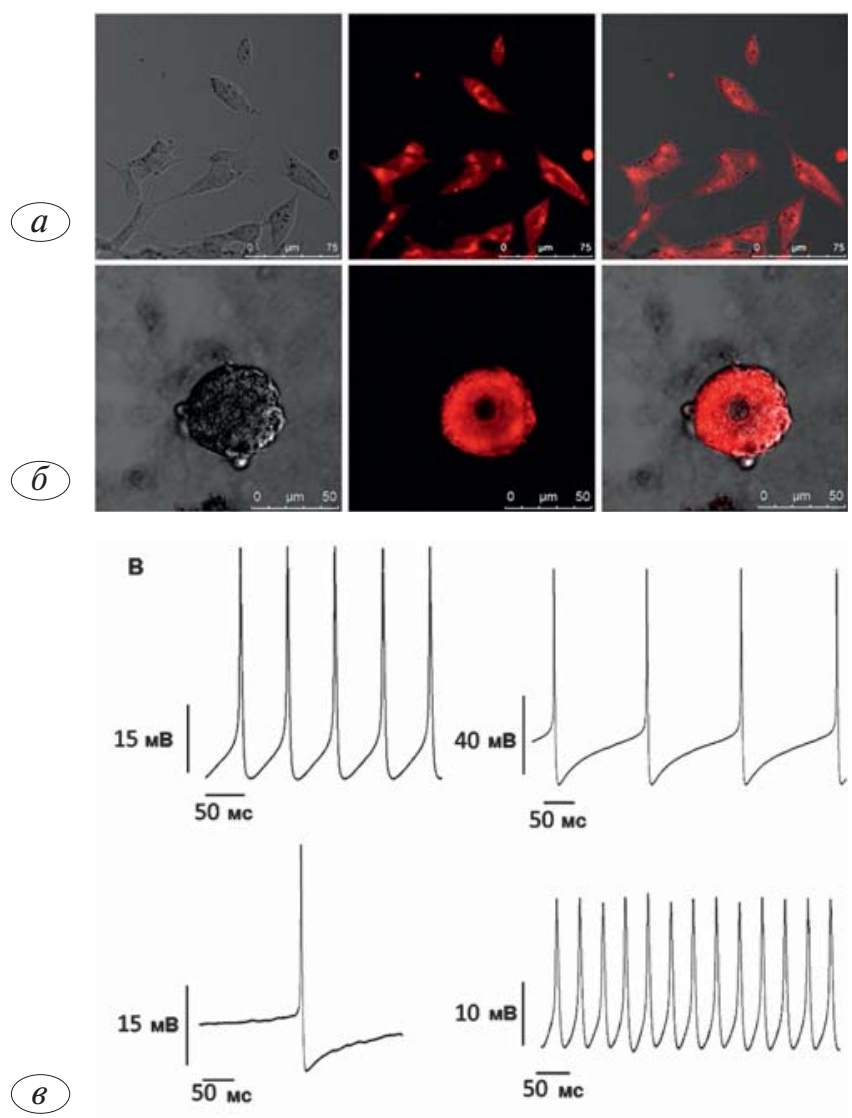

Рис. 10. Способность клеток к формированию потенциалов действия.

$a$ - конфокальные микроскопические изображения клеток линии SH-SY5Y по прошествии 24 ч инкубации с магнитными частицами (маггемитовые без покрытия); б - изображение первичного нейрона пиявки (primary leech neuron), конфокальная микроскопия, после 24 ч инкубации с магнитными частицами; в - данные электрофизиологических измерений первичных нейронов пиявок (по М. Marcus и соавт. [30]).

Fig. 10. The ability of cells to form action potentials.

$a$ - confocal microscopic images of cells of the sh-SY5Y line after 24 $\mathrm{h}$ incubation with magnetic particles (maghemite without coating); $b$-image of the primary leech neuron (primary leech neuron), confocal microscopy, after $24 \mathrm{~h}$ incubation with magnetic particles; $c$ data of electrophysiological measurements of primary leech neurons (M. Marcus et al. [30]).

не нарушает электрофизиологическую активность использованных в эксперименте нейрональных клеток. Несмотря на то что на настоящем этапе остается актуальным вопрос о подборе подходящих типов вводимых клеток, полученные данные являются существенным продвижением технологии и шагом к будущему применению этой технологии на нейронах человека.

\section{Результаты исследований на модели экспериментальных животных}

Распределение меченных магнитными частицами клеток в спинном мозге

Ответ на вопрос о распределении, принципах миграции и адгезии клеток немыслим без применения методов лучевой диагностики и гистологических исследований. Так, в своей работе, в которую были включены 32 лабораторные крысы породы Wistar, V.

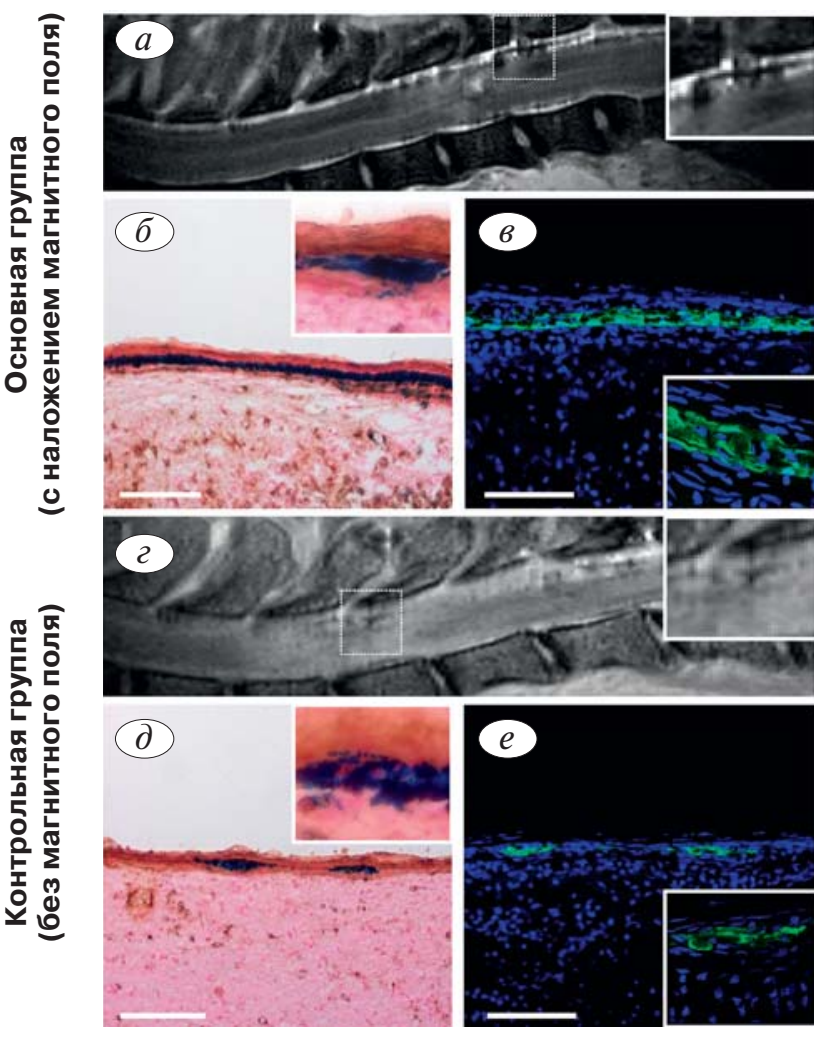

Рис. 11. Скопления клеток обладают выраженным гипоинтенсивным сигналом $(a)$, в отличие от результатов контрольной группы (2); б, в - гистологические срезы (окраска берлинской лазурью); $\partial, e-$ аналогичные исследования в контрольной группе. Масштаб: горизонтальная линия - 100 мкм (по V. Vanecek и соавт. [32]).

Fig. 11. Clusters of cells have a pronounced hypointensive signal $(a)$, in contrast to the results of the control group $(d) ; b, c-$ histological sections (color Prussian blue); $d, e-$ similar studies in the control group. Scale: horizontal line-100 microns (by V. Vanecek et al. [32]).

Vaněček и соавт. [32] использовали совмещение проведения МРТ и гистологических срезов спинного мозга животных в разные сроки с момента имплантации клеток. Результаты исследования показали, что меченные магнитными наночастицами клетки обладают выраженным гипоинтенсивным сигналом, что позволяет визуализировать их скопление при МРТ. Имплантированные клетки располагались скоплениями (кластерами) в основном в дорсальном субарахноидальном пространстве под магнитом-имплантатом. При этом была обнаружена корреляция между количеством клеток в определенной точке и напряженностью в ней магнитного поля (рис. 11).

При оценке количества мигрировавших в место повреждения клеток авторами было обнаружено, что их максимальное число достигается через 12 ч после момента имплантации, затем начинается снижение этого показателя (табл. 3).

Как видно из табл. 3, в основной группе и группе контроля динамика изменения числа клеток значительно отличается. Так, пик количества клеток в контрольной группе достигается через 24 ч (в группе с магнитным имплантатом - через 12 ч). Этот факт может свидетельствовать о том, что магнитное поле облег- 
Таб. 3. Динамика изменения количества клеток по достижении их максимальной концентрации $(n=32)$

Table 3. Dynamics of changes in the number of cells upon reaching their maximum concentration $(n=32)$

\begin{tabular}{c|c|c|}
\hline \multirow{2}{*}{$\begin{array}{c}\text { Время с момента } \\
\text { операции, ч }\end{array}$} & $\begin{array}{c}\text { Круппа с магнитным } \\
\text { имплантатом }\end{array}$ & контроль \\
\hline 12 & $\mathbf{9 5 9 5} \pm \mathbf{2 2 3 1}$ & $3538 \pm 625$ \\
\hline 24 & $7181 \pm 939$ & $\mathbf{6 8 9 4} \pm \mathbf{1 5 2 0}$ \\
\hline 72 & $3002 \pm 581$ & $1837 \pm 600$ \\
\hline 168 & $2734 \pm 174$ & $720 \pm 138$ \\
\hline
\end{tabular}

Примечание. Пик числа клеток для каждой группы отмечен полужирным шрифтом $(p<0,05)$.

чает миграцию клеток к месту повреждения (при условии соответствующей ориентации линий внешнего магнитного поля).

Также заметно, что в дальнейшем число клеток снижается. Это может говорить о наличии процессов или факторов, влияющих на их жизнеспособность, например затруднение процессов репарации ткани, миграцию в другие области или потерю жизнеспособности в магнитном поле после определенного времени. С некоторой долей осторожности можно сделать вывод, что использование магнитной системы оправдано лишь на протяжении 12 ч, затем она должна быть удалена.

\section{Восстановление неврологических функций по данным тестов}

Вопрос восстановления неврологических функций поврежденного спинного мозга занимает центральное место среди задач исследования. Наиболее важными составляющими понятия «восстановление неврологических функций» являются сроки восстановления, объем (например, степень тонуса мышц) и другие параметры, определяемые путем проведения сенсорных и двигательных тестов.

В работе [27], которая охватывала 83 лабораторных крыс породы Wistar, применялись несколько видов тестов: двигательный тест (Basso, Beattie, Bresnahan BBB); тест с отдергиванием лапы от нагретой площадки (plantar test); двигательный тест с перешагиванием балки (beam-walkuing test). Крысы были разделены на 2 группы: контрольная - животные с повреждением спинного мозга и экспериментальная группа, которой имплантировались клетки линии SPC-01 (стволовые клетки человеческого происхождения). Были получены следующие результаты (рис. 12):

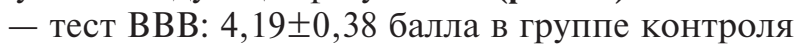

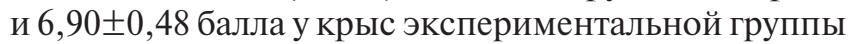
(через 9 нед после начала эксперимента, т.е. операции и трансплантации клеток). Таким образом, эксперименальная группа показала лучшие результаты по сравнению с контролем. Кроме того, по сообщению авторов, восстановление функций в экспериментальной группе не только протекало быстрее, но и началось в более ранние сроки $(p<0,05)$;

- сенсорный тест: время до отдергивания лапы составило в среднем 8,08土0,22 с у животных груп- пы контроля и 8,13 $\pm 0,20$ с - у экспериментальной. Однако, начиная с 7 нед после имплантации клеток, были отмечены значимые различия между группами, при этом в экспериментальной группе время реакции снижалось;

- двигательный тест с перешагиванием балки. По сообщению авторов, ни одно животное из группы контроля не оказалось способным перешагнуть балку за весь период наблюдения. При этом крысы, получавшие терапию клетками SPC-01, в ранние сроки после введения уже делали попытки удержания собственного веса, а некоторые из них могли перешагнуть балку. Статистически достоверные различия состояния двигательной функции регистрировались, начиная с 7 нед после имплантации SPC-01: в контрольной группе - 0,2 $\pm 0,06$ балла, в экспериментальной $2,3 \pm 0,33$ балла, что является, несомненно, более высоким результатом.

Модификация метода Т. Amemori и соавт. [27] отражена в работе A. Pal и соавт. [31]. В этом исследовании 66 животных были разделены на 4 группы:

- 18 крыс - контрольная группа, которой производилось только пересечение спинного мозга (травма - ТРM);

- 18 крыс - группа, которой проводилось введение стволовых клеток и дополнительно наложение внешнего магнитного поля (magnetic field group-MF);

- 15 крыс - группа, которой проводилась имплантация стволовых клеток, меченных магнитными наночастицами (nanoparticle group - NP);

- 15 крыс - группа, которой проводилось как наложение магнитного поля, так и введение меченных наночастицами клеток (NP+MF).

К тестам, проводимым в рамках исследования, относились: тест ВВВ; сенсорный тест «горячей площадки», тест нахождения на вращающемся горизонтальном диске (оценивалась способность крысы удерживаться на аппарате), а также время (в сут), за которое восстанавливалась функция мочевого пузыря (рис. 13).

Как видно из представленных диаграмм, восстановление неврологических функций протекает быстрее при использовании стволовых клеток, меченных магнитными наночастицами, чем без их использования. К сожалению, имеющиеся данные не раскрывают точное влияние наночастиц на эффективность клеточной терапии; целесообразным было бы также сравнение описанной терапии с базовой (без наночастиц) клеточной терапией. При этом авторами не дается детального объяснения увеличения времени задержки перед отдергиванием лапы при воздействии термального стимула в группе NP+MF. Резюмируя, можно сказать, что результаты работы требуют дальнейшего пристального изучения, несмотря на выявленный благоприятный (в рамках эксперимента) эффект.

\section{Аспекты строения и функционирования магнитных систем, применяемых в опытах in vivo}

Как и в любом другом экспериментальном исследовании, технические аспекты его выполнения име- 

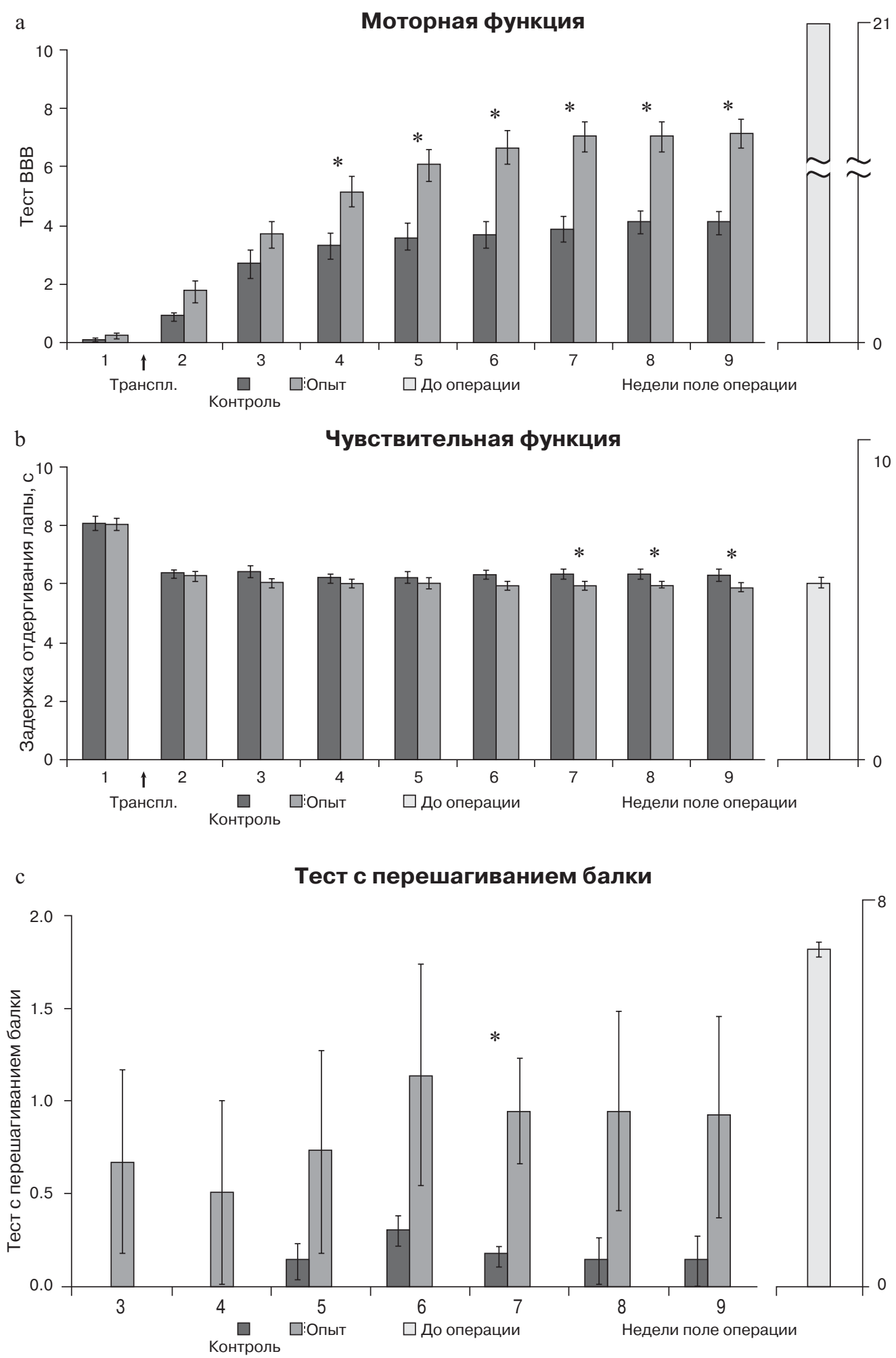

Рис. 12. Данные функционального восстановления (по Т. Amemori и соавт. [27])

Примечание. ${ }^{*}-p<0,05$. Тх - время трансплантации клеток.

Fig. 12. Functional recovery data (by T. Amemori et al. [27])

Note. ${ }^{*} p<0.05 . \mathrm{Tx}-$ time of cell transplantation

ют большое значение. Работа с магнитной системой, применяемой у лабораторных животных (с перспективой внедрения в клиническую практику), должна учитывать ряд технических особенностей, без чего ее применение будет неэффективно. Основными осо- бенностями, которые требуется учитывать при планировании применения магнитной системы, являются: характеристики магнита; форма; размеры; напряженность наложенного магнитного поля в тех или иных точках спинного мозга; зависимость количества ми- 
a

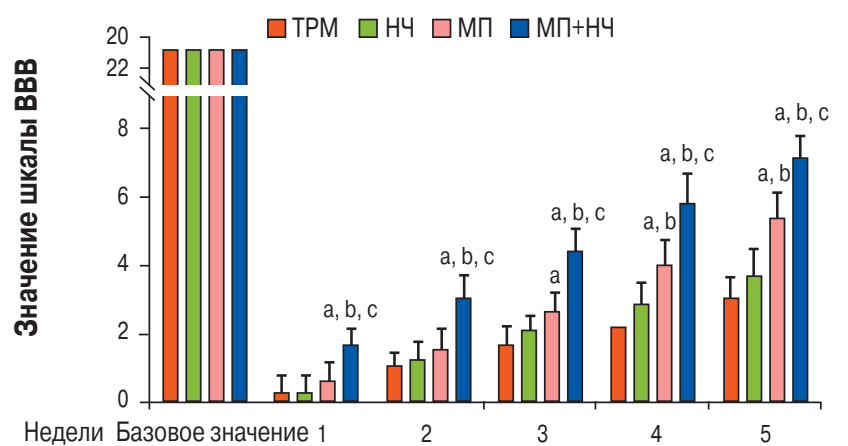

B

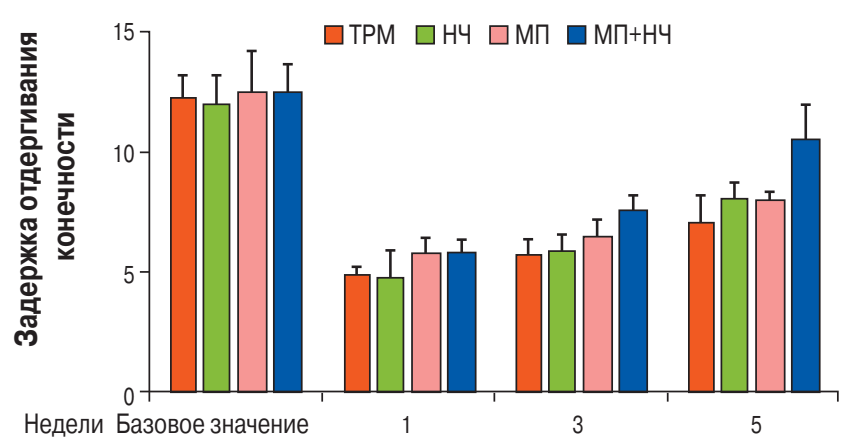

6
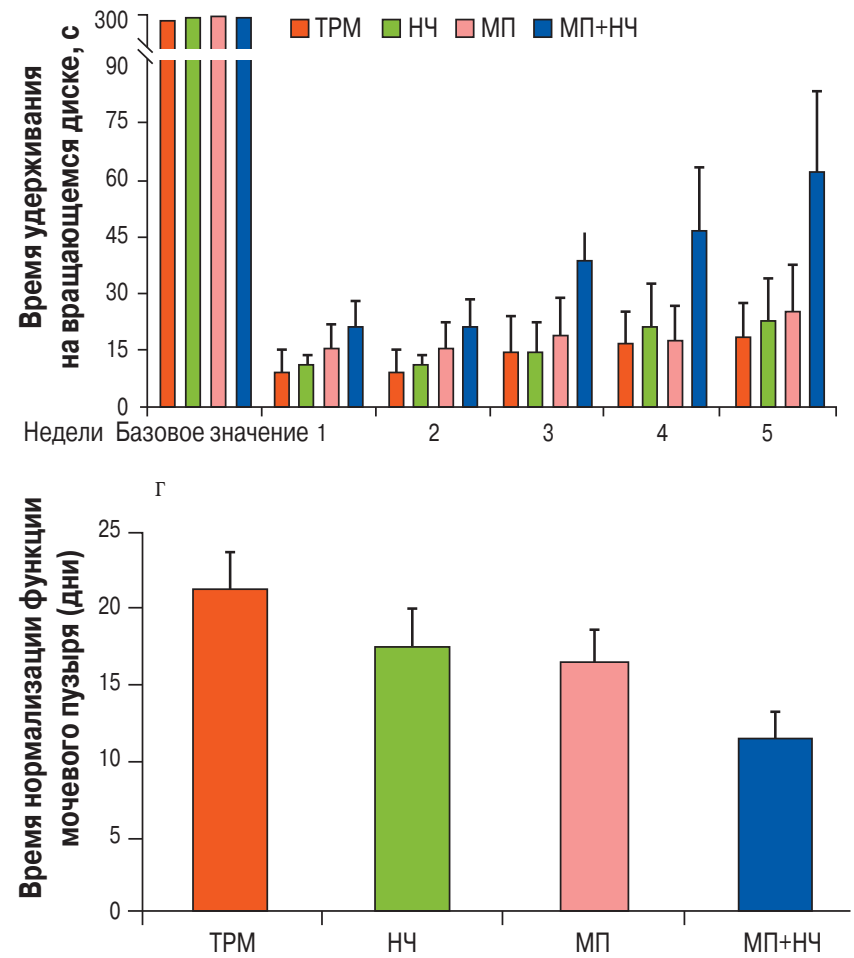

Рис. 13. Результаты функциональных тестов. ТРМ - контрольная группа (травма); НЧ - применение наночастиц; МП - наложение магнитного поля; МП+НЧ - комбинация факторов (по А. Pal и соавт. [31]).

Fig. 13. Functional test results. TRM - control group (injury); LF nanoparticle; MP - applying a magnetic field; $m+L F$ combination of factors (for A. Pal et al. [31])

грировавших клеток в месте повреждения от времени с момента их имплантации.

На момент составления обзора эти вопросы и взаимосвязь между ними максимально подробно были рассмотрены в работе V. Vaněček и соавт. [32]. В этом исследовании приводятся сведения о правильном расположении магнита в зоне повреждения соответственно ходу силовых линий магнитного поля и распределения клеток, сначала рассчитанного математически, затем экспериментально проверенного in vivo. Результаты исследования выявили неэффективность обычных (плоских) магнитов, поэтому было предложено использование ступенчатого (по форме) магнита, обеспечивающего максимальную концентрацию линий магнитного поля в области выступа, который, в свою очередь, можно расположить в проекции очага поражения (рис. 14).

Как можно заключить из рис. 14, использование ступенчатых магнитов более оправданно, поскольку позволяет поместить выступ магнита точно над местом поражения, концентрируя в нужной области возможно большее число силовых линий поля. В свою очередь этот фактор способствует накоплению клеток в очаге повреждения. Авторы, однако, подчеркивают, что магнит должен быть удален через определенное время, так как в противном случае достигнутая максимальная концентрация клеток в месте повреждения будет снижаться, что объясняется накоплением в зоне повреждения нежизнеспособных (неприжившихся) клеток и локальным дисбалансом цитокинов, затрудняющим включение имплантированных (инъецированных) клеток в восстановление очага травматического повреждения. Математическая модель, описывающая этот процесс, основана на двух основных параметрах: времени максимального накопления (создания максимальной концентрации) клеток в месте повреждения; времени, когда биологические факторы восстановления ткани начинают превалировать над действием магнита.

Временные параметры зависят от свойств клеток, магнита и местных условий (напряженность магнитного поля, размеры магнита, объем мягких тканей между магнитом и пораженным участком спинного мозга). В работе V. Vaněček и соавт. [32] эти значения были получены экспериментально на основе расчета количества клеток, оставшихся в месте повреждения по прошествии определенного времени. Представлено итоговое уравнение, описывающее зависимость снижения количества клеток от времени:

$$
N(\mathrm{t})=N_{0}\left(1-\mathrm{e}^{-t / \tau_{p h}}\right),
$$

где $N$ - количество клеток в момент времени $t, N_{o}-$ максимальная концентрация клеток, $\tau_{p h}-$ экспериментально определенная величина (так называемое характеризующее время, characteristic time), являющаяся константой для определенного эксперимента.

Экспериментальные результаты в графическом виде показаны на рис. 15-16.

Не умаляя значения работы V. Vaněček и соавт. [32], следует, однако, отметить, что математическая 


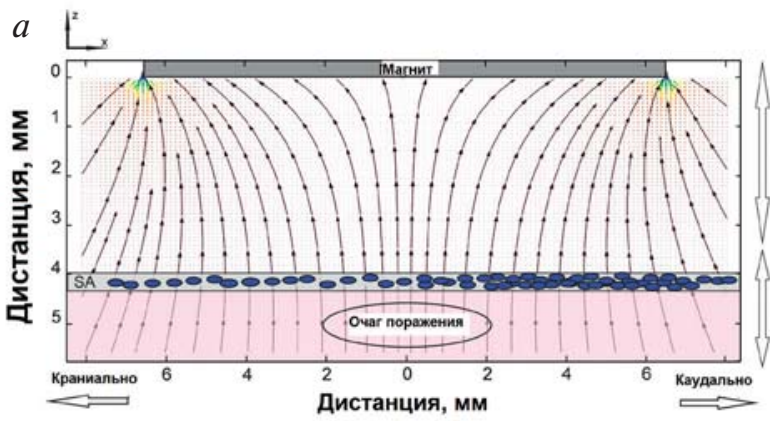

$\sigma \quad L^{2}$

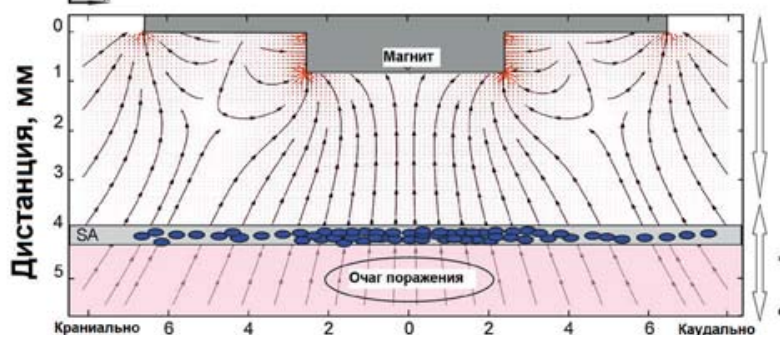

Рис. 14. Пространственное расположение клеток согласно ходу линий магнитного поля при использовании магнитов разной формы.

$a$ - плоский магнит; $\sigma$ - ступенчатый магнит. Места наибольшей напряженности магнитного поля обозначены красными, оранжевыми и зелеными точками; клетки схематически обозначены синими кругами. Видна неоднородность их распределения: у плоского магнита - по краям, у ступенчатого - в центре (по V. Vaněček и соавт. [32]).

Fig. 14. Spatial arrangement of cells according to the course of the magnetic field lines when using magnets of different shapes. $a-$ flat magnet; $b$ - «stepped» magnet. Places of the greatest intensity of the magnetic field are marked with red, orange and green dots; cells are schematically marked with blue circles. Visible the heterogeneity of their distribution: the flat magnet - the edges, the speedin the center (V. Vaněček et al. [32]). модель, описывающая процессы изменения количества клеток в месте травматического повреждения, требует дальнейшей разработки. В качестве конечной прикладной цели можно указать создание алгоритмов, позволяющих подобрать размеры магнита и другие особенности магнитной системы (характеристики частиц и клеток) для планирования терапии у конкретного пациента.

\section{Результаты применения метода в клиническом эксперименте}

В настоящее время исследователями предпринимаются активные попытки применить исследуемую технологию в клиническом эксперименте. Так, в 2015 г. была опубликована работа A. Chotivichit и соавт. [33], в которой отражена первая (описанная в литературе) попытка доставить стволовые клетки в место повреждения, используя внешнее магнитное поле и магнитные наночастицы.

В исследование был вовлечен 33-летний пациент с повреждением спинного мозга на уровне сегментов CI-CII вследствие атланто-аксиального подвывиха; при этом, по данным МРТ, у больного имелась компрессия спинного мозга задней дугой атланта. Пациенту была произведена тракция, иммобилизация ортезом Halo-Vest. Через 4 года после операции пациент по-прежнему находился на искусственной вентиляции легких (ИВЛ), у него наблюдались тетрапарез и хронический нейропатический болевой синдром. Пациенту после получения информированного добровольного согласия была выполнена аутотрансплантация стволовых клеток, взятых из гребня подвздошной кости в составе ткани костного мозга. Особенности подготовки клеток описаны в разделе «Материал и методы». $a$

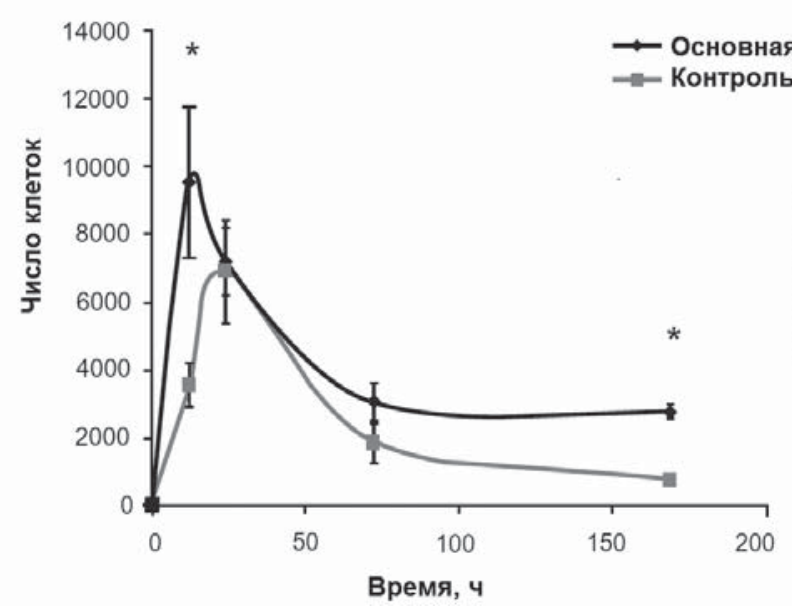

$\sigma$

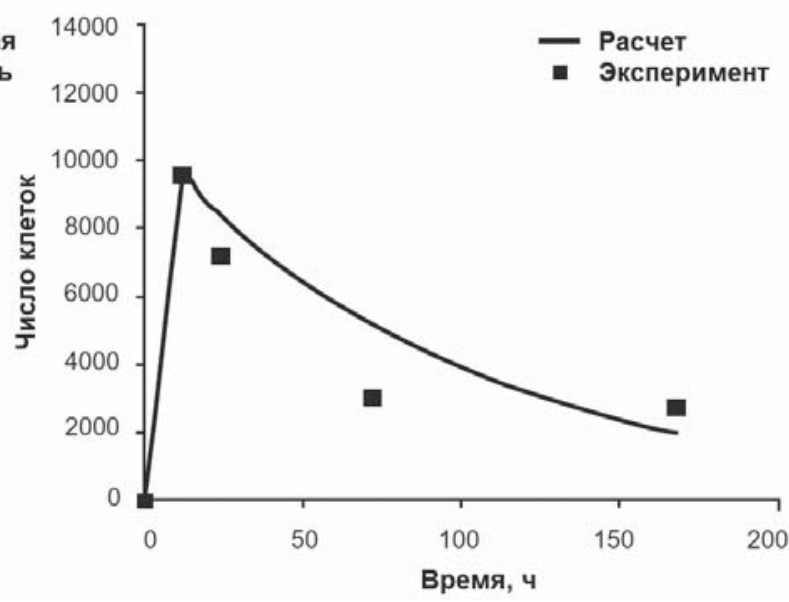

Рис. 15. Зависимость количества клеток в очаге поражения от времени.

Слева: черная линия - концентрация клеток при использовании магнита, серая - без использования магнита. Справа: сравнение математически рассчитанных и наблюдаемых в эксперименте результатов (по V. Vaněček и соавт. [32]).

Fig. 15. The dependence of the number of cells in the lesion on time. Left: black line - the concentration of cells when using a magnet, graywithout the use of a magnet. Right: comparison of mathematically calculated and experimentally observed results (by V. Vaněček et al. [32]).2]). 

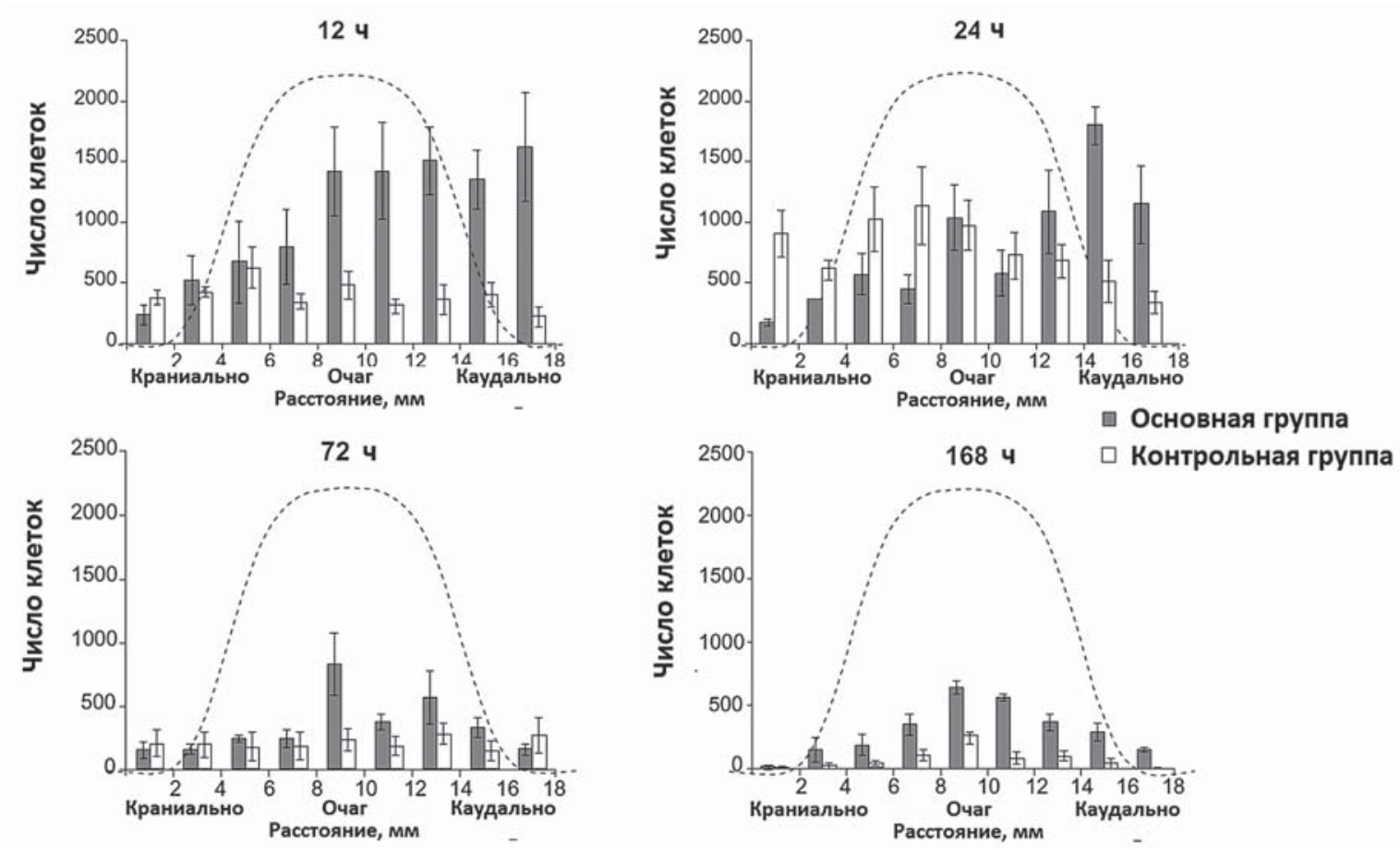

Рис. 16. Экспериментально зафиксированные результаты количественного распределения клеток на протяжении участка поврежденного спинного мозга крысы (18 см), включая, но не ограничиваясь зоной повреждения.

Пунктиром обозначена математически рассчитанная напряженность магнитного поля плоского магнита в зависимости от положения определенной точки на краниально-каудальной «оси». Большее количество клеток в каудальном отделе по сравнению с краниальным отделом объясняется техническими причинами, а именно - введением клеток путем люмбальной пункции (по V. Vaněс̌еk и соавт. [32]).

Fig. 16. Experimentally recorded results of quantitative distribution of cells throughout the area of the damaged rat spinal cord (18 cm), including but not limited to the area of damage. The dotted line indicates the mathematically calculated magnetic field strength of a flat magnet depending on the position of a certain point on the cranial-caudal «axis». The greater number of cells in the caudal Department compared to the cranial Department due to technical reasons, namely - the introduction of cells by lumbar puncture (V. Vaněček et al. [32])

Неврологический статус пациента вернулся к дооперационному через 12 ч. Тем не менее в первые 48 ч отмечались миалгия, головная боль. Краткие результаты изменения состояния пациента в пределах 12 мес после операции отражены в табл. 4.

Авторами отмечается, что выраженного улучшения неврологических функций выявлено не было. Тем не менее на картине МРТ определялось накопление трансплантированных стволовых клеток в субарахноидальном пространстве поясничного отдела спинного мозга и области конского хвоста (cauda equina) (рис. 17).

По данным МРТ, клетки были обнаружены в области нижних (каудальных) отделов позвоночника и спинного мозга, что может быть связано с действием гравитации. Этим в свою очередь можно объяснить отсутствие улучшения состояния пациента в период после оперативного вмешательства, поскольку клетки не проникли к месту повреждения (в рассматриваемом клиническом примере оно находилось в верхних шейных сегментах спинного мозга). Кроме того, значительное время, прошедшее после травмы (4 года), является фактором, значительно снижающим прогноз всех видов терапии в отношении неврологического (двигательного, чувствительного) статуса.
Авторами работы было высказано предположение, что помещение пациента в положение Тределенбурга может оказаться достаточным для миграции клеток под действием гравитации из поясничной области в вышележащие отделы. Однако после возврата пациента в «обычное» положение клетки могли мигрировать каудально, не адгезируя к поврежденному сегменту (рис. 18).

По мнению авторов, клетки могут мигрировать под действием силы гравитации в вышележащие отделы спинного мозга (например, при нахождении пациента в положении Тределенбурга), т.е. подобный ход событий теоретически возможен. Вместе с тем они заявляют о необходимости дальнейших исследований.

K сожалению, авторами не делается значимый акцент на причинах транзиторного (на протяжении 12 ч) ухудшения неврологического статуса после введения клеток, которые предстоит выяснить для развития технологии имплантации стволовых клеток.

На основе всей представленной информации возможно сделать вывод, что основное затруднение для терапии меченными магнитными наночастицами повреждений спинного мозга заключается в проблеме доставки клеток к месту повреждения и долговременной адгезии к нему. 
Табл. 4. Сумма клинических данных пациента с повреждением спинного мозга до и после операции Table 4. Sum of clinical data of a patient with spinal cord injury before and after surgery

\begin{tabular}{|c|c|c|c|c|}
\hline \multirow{2}{*}{ Показатель } & \multirow{2}{*}{$\begin{array}{c}\text { Состояние } \\
\text { до операции }\end{array}$} & \multicolumn{3}{|c|}{ Состояние после операции } \\
\hline & & 2 сут & $6 \mathrm{мес}$ & $12 \mathrm{mec}$ \\
\hline Значение по шкале нарушения неврологических функций ASIA & B & B & B & B \\
\hline Потребность в ИВЛ & Да & Да & Да & Да \\
\hline \multicolumn{5}{|l|}{ Оценка двигательной функции, баллы } \\
\hline верхние конечности & 18 & 10 & 18 & 18 \\
\hline нижние конечности & 4 & 2 & 4 & 4 \\
\hline \multicolumn{5}{|l|}{ Сенсорная функция, баллы } \\
\hline ответ на тактильный раздражитель & 109 & 109 & 109 & 109 \\
\hline ответ на болевой раздражитель & 108 & 108 & 108 & 108 \\
\hline Нейропатические боли & + & + & + & ++ \\
\hline
\end{tabular}

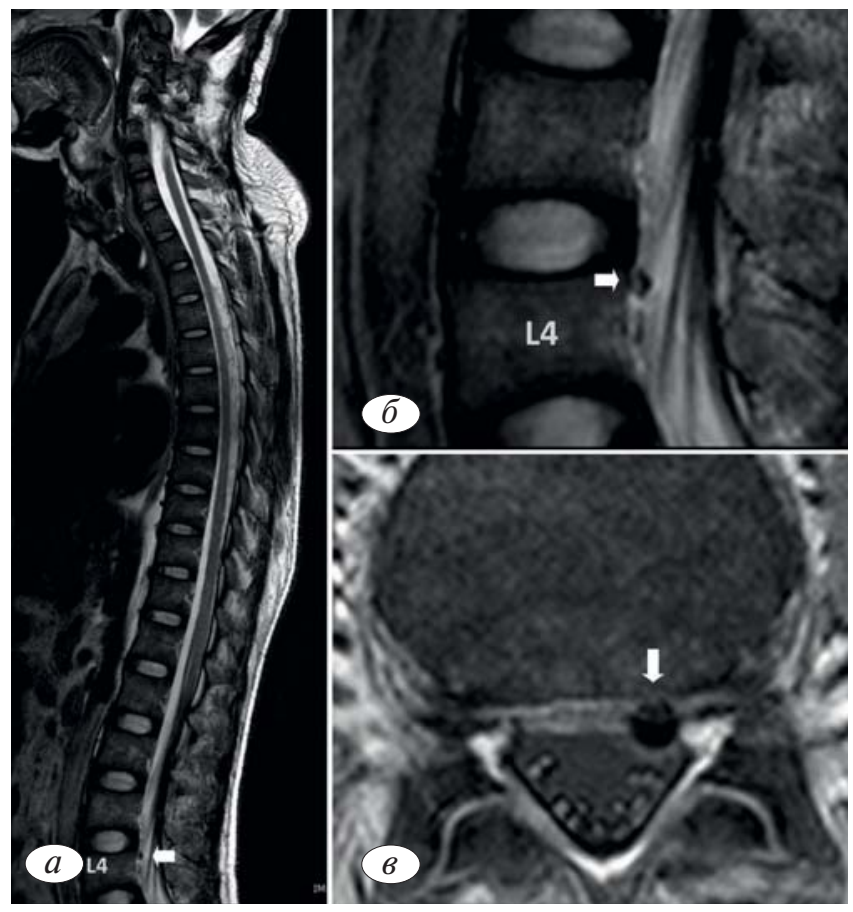

Рис. 17. Изображение МРТ пациента с повреждением спинного мозга (33 года) в области шейного отдела позвоночника, полученное через 1 сут после введения меченных магнитными наночастицами клеток путем люмбальной пункции.

Сагиттальные Т2-взвешенные изображения позвоночника в целом (a) и фрагмента поясничного отдела (б); в - аксиальное изображение позвонка LIV. Белыми стрелками на всех изображениях отмечено накопление меченных магнитными наночастицами клеток. В шейном отделе спинного мозга клетки обнаружены не были (по А. Chotivichit и соавт. [33]).

Fig. 17. MRI image of a patient with spinal cord injury (33 years) in the cervical spine, obtained 1 day after the introduction of magnetic nanoparticle-labeled cells by lumbar puncture. Sagittal T2-weighted images of the spine as a whole (a) and a fragment of the lumbar spine (b); C - axial image of the vertebra LIV. White arrows on all images indicate the accumulation of magnetic nanoparticle-labeled cells. In the cervical spinal cord cells were not found (for A. Chotivichit et al. [33]).

Заключение. Использование магнитных наночастиц - перспективный экспериментальный метод, который в будущем, вероятно, может стать ценным дополнением к клеточной терапии в лечении острой и хронической спинальной травмы с повреждением спинного мозга. В настоящем обзоре был рассмотрен обширный материал, охватывающий различные аспекты терапии стволовыми клетками, меченными магнитными наночастицами, различных повреждений. На основании проанализированного материала можно сделать следующие выводы:

1. Меченные магнитными наночастицами клетки способны мигрировать во внешнем (наложенном) магнитном поле. Направление миграции диктуется плотностью линий магнитного поля: клетки смещаются в ту зону, где она наибольшая.

2. В отсутствие магнитного поля клетки располагаются хаотично и относительно однородно, не образуя скоплений, характерных для пространственного распределения их в магнитном поле.

3. Захват магнитных наночастиц опосредован различными клеточными механизмами, при этом частицы локализуются в цитоплазме клеток. Клеточные механизмы захвата частиц работают, независимо друг от друга, однако в зависимости от размеров частиц и особенностей (типа, заряда) покрытия могут характеризоваться избирательностью в отношении тех или иных разновидностей частиц.

4. Не получено данных, свидетельствующих о выраженной цитотоксичности магнитных наночастиц различных типов. Кроме того, по некоторым данным (см. раздел «Цитотоксичность»), магнитные наночастицы на основе оксида железа (II), (III), (II, III) способны оказывать цитопротективный эффект в отношении свободных радикалов, в частности гидроксид-радикала, что в свою очередь способствует выживаемости клеток.

5. Не выявлено статистически достоверного негативного влияния магнитных наночастиц на процессы ветвления тех типов клеток (линий), которые обладали этой способностью изначально. Этот факт представляется важным, так как процессы образования клеточных отростков при потенциальной дифференцировке стволовых клеток в зоне травматического поражения спинного мозга не будут нарушены. То же показано и в отношении электрофизиологической активности нейронов низших животных (пиявок). В рецензии упоминалось, что МСК не обладают подобными свойствами. Однако принято решение о МСК не писать: они не подходят ни в каком аспекте. 


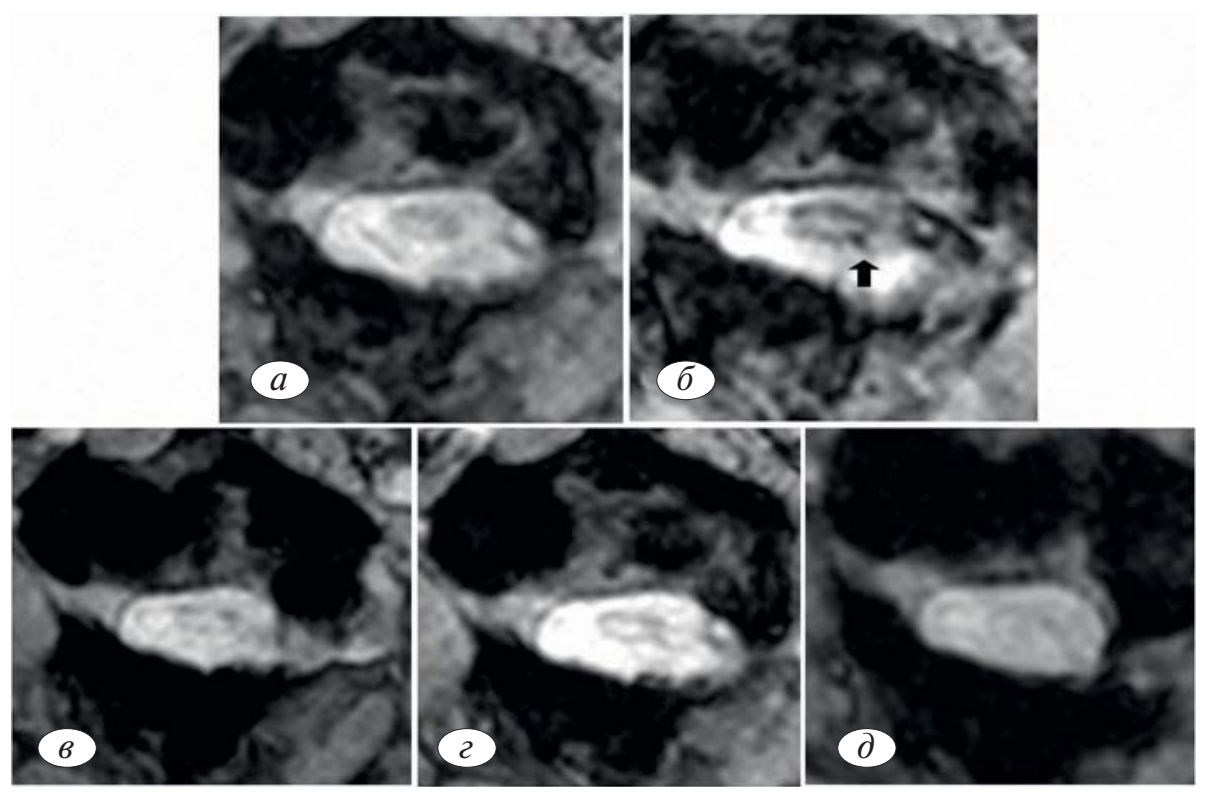

Рис. 18. МРТ-изображения сегмента СI спинного мозга, полученные в различные сроки после операции:

$a$ - состояние до операции; $6-2$ сут после операции; $в-2$ нед; $2-1$ мес, $\partial-7$ мес. Стрелкой показан очаг накопления меченных магнитными частицами стволовых клеток, который на более поздних МР-томограммах не определяется (по А. Chotivichit и соавт. [33]).

Fig. 18. MRI images of the segment CI of the spinal cord obtained at different times after surgery: $a$ - state before surgery; $b-2$ days after surgery; $b-2$ weeks; $g-1$ month, $d-7$ months. The arrow shows the «hearth» of the accumulation of magnetic particles labeled stem cells, which later on Mr-tomograms is not defined (for Chotivichit A. et al. [33])

6. При исследованиях in vivo показано, что максимальная концентрация меченных магнитными наночастицами клеток создается в месте травматического повреждения спустя 12 ч после трансплантации (субарахноидальной инъекции) клеток при условии наличия магнитного поля. При отсутствии магнитного поля максимальная концентрация достигается спустя приблизительно 24 ч, что позволяет сделать вывод об ускорении меченных магнитными частицами клеток магнитным полем.

7. После достижения максимальной концентрации число клеток экспоненциально снижается, что может быть вызвано негативным влиянием магнитного поля на выживаемость клеток (например, ограничением их миграции в пределах зоны травматического повреждения). Согласно имеющимся на текущий момент данным, нахождение магнитной системы в области повреждения после достижения максимальной концентрации клеток нецелесообразно.

8. По данным экспериментов in vivo, у всех групп лабораторных животных, получавших терапию меченными магнитными метками стволовыми клетками, зарегистрировано улучшение неврологических функций (как двигательной, так и сенсорной) при прохождении различных тестов. Несмотря на неполное восстановление в период наблюдения (до 9 нед с момента имплантации клеток), различную скорость и время статистически значимого начала восстановления функций, все экспериментальные группы животных продемонстрировали положительную динамику восстановления по сравнению с контрольной группой. Исходя из имеющихся сведений, можно сделать вывод, что терапия стволовыми клетками, меченными магнитными наночастицами, является перспективным методом лечения травматических повреждений спинного мозга; следует уделять большее внимание началу использования метода в условиях клинических испытаний (с соблюдением этических норм).

9. Использование магнитных систем имеет ряд технических особенностей, влияющих на пространствен- ное распределение клеток в области зоны травматического поражения. Согласно имеющимся данным, необходимо использовать ступенчатые, а не плоские магниты, поскольку в области их выступа создается максимальная плотность линий магнитного поля (и соответственно максимальная концентрация клеток), что позволяет точно сориентировать магнит (выступ должен располагаться в проекции центра зоны поражения). В то же время у плоского магнита максимальная плотность линий поля достигается в области полюсов, и при помещении центра такого магнита над центром зоны повреждения концентрация клеток в последнем будет весьма низкой.

10. В настоящее время предпринимаются попытки расширения применения метода от лабораторных испытаний в сторону клинического эксперимента. Значимых результатов в настоящее время не достигнуто по причине трудности удержания клеток в очаге поражения в течение длительного периода. Кроме того, такие попытки единичны, и для полноценного решения вопроса о возможностях и ограничениях применения данного метода требуется вовлечение в исследование как можно большего числа больных.

Несмотря на некоторые обнадеживающие результаты, вышеописанный метод остается экспериментальным, а многие аспекты требуют дополнительного изучения. В качестве мер и предложений по развитию данного метода, с учетом полученных результатов, можно выделить следующие.

1) Решение вопроса о подборе линий клеток, подходящих для терапии у пациентов, в том числе в ходе экспериментального лечения. Данный аспект - coвершенно необходимый шаг к планированию клинических испытаний описываемой биомедицинской технологии

2) Остается открытым вопрос об эффективности терапии магнитными наночастицами в различные сроки с момента получения травмы. Для его решения также необходимо включить в исследование большее число пациентов на разных сроках с момента 
получения травмы. Учитывая развитие дегенеративных процессов ткани поврежденного спинного мозга в отдаленные сроки (месяцы и годы), в частности мало- или инкурабельных сирингомиелиновых кист $[17,34]$, можно предположить, что терапия в краткие сроки (недели с момента получения травмы) будет иметь лучший прогноз, чем в отдаленные. В случае, если указанная взаимосвязь между сроком терапии после травмы и прогнозом будет обнаружена, можно статистически определить точные временные рамки наиболее благоприятного для терапии периода (аналогично так называемому «золотому часу» в реаниматологии).

3) Ответить на вопрос: «Влияет ли уровень повреждения спинного мозга на прогноз терапии?» Данный пункт требуется осветить по причине неодинакового строения спинного мозга на его протяжении (в частности, наличие или отсутствие в определенных сегментах парасимпатических ядер и связей с симпатическим стволом через белые и серые соединительные ветви, особенностей кровоснабжения - так, в шейном сегменте кровоснабжение (и соответственно условия для приживления клеток) может потенциально быть лучше за счет мелких ветвей позвоночных артерий.

4) Ответить на вопрос: «Как доставить меченные магнитными частицы к месту повреждения спинного мозга на том или ином уровне?» Актуальность данной проблемы подробно освещена в главе «Результаты применения метода в клинической практике».

5) Ответить на вопрос: «Каков прогноз терапии при частичных повреждениях спинного мозга и отличается ли он от прогноза у пациентов с полным повреждением спинного мозга на том же уровне и теми же сроками с момента травмы?»

6) Ответить на вопрос: «Есть ли и какова взаимосвязь между наличием неврином нервных волокон в проксимальном фрагменте спинного мозга после его перерыва и эффективностью терапии магнитными наночастицами (восстановления нервной ткани)?» Для ответа целесообразно использовать экспериментальную модель с использованием гистологических срезов проксимального отдела пересеченного спинного мозга лабораторных животных.

7) Выработать единые стандарты проведения исследования, что значительно облегчит анализ результатов имеющихся работ и планирование будущих экспериментов. В качестве примера можно привести использование клеток одной линии (либо как можно более сходных филогенетически и гистологически клеточных линий) в различных экспериментах.

Стоит отметить, что для ответа на все перечисленные вопросы требуется включение в выборку новых пациентов, что позволит получить статистически достоверные данные.

\section{Л И Т Е Р А Т У $\mathrm{PA}$ [ R E F E R E N C E S ]}

1. Talac R., Friedman J., Moore M. Animal models of spinal cord injury for evaluation of tissue engineering treatment strategies. Biomaterials. 2004;25(9):1505-10.
2. Kubinova S., Sykova E. Biomaterials combined with cell therapy for treatment of spinal cord injury. Regen Med. 2012;7(2):20724.

3. Sykova E., Homola A., Mazanec R. Autologous bone marrow transplantation in patients with subacute and chronic spinal cord injury. Cell Transplant. 2006;15(8-9):675-87.

4. Arboleda D., Forostyak S., Jendelova P. Transplantation of predifferentiated adipose-derived stromal cells for the treatment of spinal cord injury. Cell Mol Neurobiol. 2011;31(7):1113-22.

5. Paul C., Samdani A., Betz R., Fischer I., Neuhuber B. Grafting of human bone marrow stromal cells into spinal cord injury: a comparison of delivery methods. Spine (Phila Pa 1976) 2009;34:328-34.

6. Jendelova P., Herynek V., Urdzhikova L. Magnetic resonance tracking of transplanted bone marrow and embryonic stem cells labeled by iron oxide nanoparticles in rat brain and spinal cord J Neurosci Res. 2004;76(2):232-43.

7. Sykova E., Jendelova P. Magnetic resonance tracking of implanted adult and embryonic stem cells in injured brain and spinal cord. Ann New York Acad Sci. 2005;1049:146-60.

8. Huang Z., Pei N., Wang Y. Deep magnetic capture of magnetically loaded cells for spatially targeted therapeutics. Biomaterials. 2010;31(8):2130-40

9. Wilheim C., Bal L., Smirnov P. Magnetic control of vascular network formation with magnetically labeled endothelial progenitor cells. Biomaterials. 2007;28(26):3797-806.

10. Arbab A., Jordan E., Wilson L., Yocum G., Lewis B., Frank J In vivo trafficking and targeted delivery of magnetically labeled stem cells. Hum Gene Ther. 2004;15(4):351-60

11. Song M., Kim Y., Kim Y., Roh J., Kim S, Yoon B. Using a neodymium magnet to target delivery of ferumoxide-labeled human neural stem cells in a rat model of focal cerebral ischemia. Hum Gene Ther. 2010;21(5):603-10.

12. Nishida K., Tanaka N., Nakanishi K. Magnetic targeting of bone marrow stromal cells into spinal cord: through cerebrospinal fluid. Neuroreports. 2006;17(12):1269-72.

13. Tukmachev D., Lunov O., Zablotskii V., Dejneka A., Babic M., Sykova E. et al. An effective strategy of magnetic stem cell delivery for spinal cord injury therapy. Nanoscale. 2015;7(9): 3954-8.

14. Holle A., Engler A. Cell rheology: Stressed-out stem cells. Nat Mater. 2010;9:4-6.

15. Cho H., Choi Y., Lee D., Park H., Seo Y., Jung H. et al. Effects of magnetic nanoparticle-incorporated human bone marrowderived mesenchymal stem cells exposed to pulsed electromagnetic fields on injured rat spinal cord. Biotechnol Appl Biochem. 2013;60(6):596-602.

16. Cores J., Caranasos T., Cheng K. Magnetically targeted stem cell delivery for regenerative medicine. J Funct Biomater. 2015 6:526-46.

17. Mahmoudi M., Sant S., Wang B., Laurent S., Sen T. Superparamagnetic iron oxide nanoparticles (SPIONs): Development, surface modification and applications in chemotherapy. Adv Drug Deliv Rev. 2011;63:24-46.

18. Sheng-nan S., Chao W., Zan-zan Z. Magnetic iron oxide nanoparticles: Synthesis and surface coating techniques for biomedical applications. Chin Phys. 2014;23:1-19.

19. Umut $E$. Surface modification of nanoparticles used in biomedical applications. Mod Surf Eng Treat. 2013;5:185-208.

20. Tassa C., Shaw S., Weissleder R. Dextran-coated iron oxide nanoparticles: A versatile platform for targeted molecular imaging, molecular diagnostics, and therapy. Acc Chem Res. 2011 44:842-52

21. Usher T., Walls $S$. Process of Making Carboxylated Dextran. Canada: SMART \& BIGGAR; 2004

22. Yi G., Li S., Wang S., Moore R. Nanomedicine. New York: Springer; 2014.

23. Cortajarea A., Ortega D., Ocampo S., Gonzalez-Garcia A., Couleaud P., Miranda R. et al. Engineering iron oxide nanoparticles for clinical settings. Nanobiomedicine; 2014.

24. Hillaireau H., Couvreur P. Nanocarriers' entry into the cell: Relevance to drug delivery. Cell Mol Life Sci. 2009;66:2873-96.

25. Cheung K., Shen D., Hensley T., Middleton R., Sun B., Liu W. et $a l$. Magnetic antibody-linked nanomatchmakers for therapeutic cell targeting. Nat Commun. 2014;5:4880. 
26. Tang J., Shen D., Zhang J., Ligler F., Cheng K. Bispecific antibodies, nanoparticles and cells: Bringing the right cells to get the job done. Expert Opin Biol Ther. 2015;15(9):1-5.

27. Amemori T., Romanyuk N., Jendelova P. Human conditionally immortalized neural cells improve locomotor function after spinal cord injury in the rat. Stem Cell Res Ther. 2013;4:68.

28. Cocks G., Romanyuk N., Amemori T. Conditionally immortalized stem cell lines from human spinal cord retain regional identity and generate functional V2a interneurons and motorneurons. Stem Cell Res Ther. 2013;4(69):110.

29. Zablotskii V., Dejneka A., Kubinova S., Le-Roy D., DumasBouchiat F. Life on Magnets: Stem Cell Networking on MicroMagnet Arrays. PLoS One. 2013;8(8):e70416.

30. Marcus M., Moshe K., Baranes K., Levy I., Alon N., Martel S. et al. Iron oxide nanoparticles for neuronal cell applications: uptake study and magnetic manipulations. J Nanobiotechnology. 2016;14(37):1447.

31. Pal A., Singh A., Nag T. Iron oxide nanoparticles and magnetic field exposure promote functional recovery by attenuating free radical-induced damage in rats with spinal cord transection. Int J Nanomedicine. 2013;8:2259-72.

32. Vanecek V., Zablotskii V., Forostyak S. Highly efficient magnetic targeting of mesenchymal stem cells in spinal cord injury. Int $\mathbf{J}$ Nanomedicine. 2012;7:3719-30.

33. Chotivichit A., Ruangchainikom M., Chiewvit P. Chronic spinal cord injury treated with transplanted autologous bone marrowderived mesenchymal stem cells tracked by magnetic resonance imaging: a case report. J Med Case Rep. 2015;9(79):111.
34. Riggio C., Nocentini S., Catalayd M. Generation of magnetized olfactory ensheating cells for regenerative studies in the central and peripheral nervous tissue. Int J Mol Sci. 2013;14:10852-68.

35. Margel S., Gura S. Nucleation and growth of magnetic metal oxide nanoparticles and its use. Israel; WO9962079; 2006.

36. Nakamura M., Okano $H$. Cell transplantation therapies for spinal cord injury focusing on induced pluripotent stem cells. Cell Res. 2013;23:70-80.

37. Connell J., Patrick P., Yu Y., Lythgoe M., Kalber T. Advanced cell therapies: targeting, tracking and actuation of cells with magnetic particles. Regen Med. 2015;10:757-72.

38. Foged C., Brodin B., Frokjaer S., Sundblad A. Particle size and surface charge affect particle uptake by human dendritic cells in an in vitro model. Int J Pharmacol. 2005;298:315-22.

39. Kim J., Lee N., Kim B., Rhee W., Yoon S., Hyeon T. et al. Enhancement of neurite outgrowth in PC-12 cells by iron oxide nanoparticles. Biomaterials. 2011;32:2871-7.

40. Mahmoudi M., Hofmann H., Rothen-Rutishauser B., Petri-Fink A. Assessing the in vitro and in vivo toxicity of superparamagnetic iron oxide nanoparticles. Chem Rev. 2012;112:2323-38.

41. Meng X., Seton H., Lu L., Prior I., Thanh N., Song B. Magnetic $\mathrm{CoPt}$ nanoparticles as MRI contrast agent for transplanted neural stem cells detection. Nanoscale. 2011;3:977-84.

42. Taylor A., Hermann A., Moss D., Sée V., Davies K., Williams $S$ et al. Assessing the efficacy of nano- and micro-sized magnetic particles as contrast agents for MRI cell tracking. PLoS One. 2014;9:e100259.

Сведения об авторах: Колесов Сергей Васильевич - д.м.н., проф., заведующий отделением патологии позвоночника НМИЦ ТО им. Н.Н. Приорова, e-mail: dr-kolesov@yandex.ru; Швеи, Владимир Викторович - д.м.н., ведущий научный сотрудник отделения патологии позвоночника НМИЦ ТО им. Н.Н. Приорова, e-mail: vshvetcv@yandex.ru; Сажнев Максим Леонидович - к.м.н., врач отделения патологии позвоночника НМИЦ ТО им. Н.Н. Приорова, e-mail: mak.sajnev@yandex.ru; Пантелеев Андрей Андреевич - врач отделения патологии позвоночника НМИЦ ТО им. Н.Н. Приорова, e-mail:??; Горбатюк Дмитрий Сергеевич - младший научный сотрудник НМИЦ ТО им. Н.Н. Приорова, e-mail: naddis@mail.ru.

Для контактов: Колесов С.В. - e-mail: dr-kolesov@yandex.ru

Information about the authors: Kolesov S.V. - MD, Prof., head of the Department of spinal pathology N.N. Priorov National Medical Research Center of Traumatology and Orthopaedics, Moscow, Russia; Shvets V.V. - doctor of medical Sciences, leading researcher of Department of pathology of the spine N.N. Priorov National Medical Research Center of Traumatology and Orthopaedics; Sazhnev M.L. - PhD, physician pathology of the spine N.N. Priorov National Medical Research Center of Traumatology and Orthopaedics; Panteleyev A.A. - doctor Department of pathology of the spine N.N. Priorov National Medical Research Center of Traumatology and Orthopaedics; Gorbatyuk D.S. - Junior researcher N.N. Priorov National Medical Research Center of Traumatology and Orthopaedics, e-mail: naddis@mail.ru.

Contact: Kolesov S.V. e-mail: dr-kolesov@yandex.ru 